$10-23-2018$

\title{
Funding Liquidity Shocks in a Quasi-Experiment: Evidence from the CDS Big Bang
}

Xinjie Wang

Southern University of Science and Technology

Yangru Wu

Rutgers University, Newark

Hongjun Yan

DePaul University

Zhaodong Zhong

Rutgers, The State University of New Jersey

Follow this and additional works at: https://via.library.depaul.edu/buspubs

Part of the Business Commons

\section{Recommended Citation}

Wang, Xinjie and Wu, Yangru and Yan, Hongjun and Zhong, Zhaodong, Funding Liquidity Shocks in a Quasi-Experiment: Evidence from the CDS Big Bang (October 23, 2018). 29th Australasian Finance and Banking Conference 2016. Available at SSRN: https://ssrn.com/abstract=2730877 or http://dx.doi.org/ $10.2139 /$ ssrn. 2730877

This Article is brought to you for free and open access by the Driehaus College of Business at Digital Commons@DePaul. It has been accepted for inclusion in Publications - Dreihaus College of Business by an authorized administrator of Digital Commons@DePaul. For more information, please contact digitalservices@depaul.edu. 


\section{Funding Liquidity Shocks in a Quasi-Experiment: Evidence from the CDS Big Bang*}

\author{
Xinjie Wang \\ SUSTech \\ Hongjun Yan \\ DePaul University
}

\author{
Yangru Wu \\ Rutgers University \\ Zhaodong (Ken) Zhong ${ }^{\S}$ \\ Rutgers University
}

October 23, 2018

Keywords: funding liquidity, CDS Big Bang, CDS Small Bang, standardization, central clearing JEL Classification: G11, G12, G13, G14, G18, G28

\footnotetext{
* We thank Jennie Bai, Bo Becker, Bruno Biais, Patrick Bolton, James Dow, Darrell Duffie, William Fuchs, Benjamin Golez, Florian Heider, Anastasia Kartasheva, David Lando, Ji-Chai Lin, Sebastien Michenaud, Ailsa Roell, David Skeie, Dragan Tang, Baolian Wang, Sarah Wang, John Wei, Hong Yan, Fan Yu, and seminar or conference participants at American Finance Association Annual Meeting, Australasian Finance and Banking Conference, CEPR European Summer Symposium in Financial Markets, China International Conference in Finance, European Winter Finance Conference, Financial Management Association Annual Meeting, Hong Kong Polytechnic University, Shanghai Advanced Institute of Finance, and Triple Crown Conference for their helpful comments. Xinjie Wang acknowledges financial support from Southern University of Science and Technology under the Startup Grant (Y01246210, Y01246110).

$\S$ Corresponding author. Address: Department of Finance and Economics, Rutgers Business School, Rutgers University, 100 Rockafeller Road, Piscataway, NJ 08854; Tel: 1-848-445-5109; Fax: 1-732-445-2333; E-mail: zdzhong@business.rutgers.edu.
} 


\title{
Funding Liquidity Shocks in a Quasi-Experiment: Evidence from the CDS Big Bang
}

\begin{abstract}
A major change in trading conventions in April 2009, the so-called "CDS Big Bang," induces upfront fees for trading North American CDSs. Exploiting this quasi-experiment, we provide evidence that upfront fees have a differential effect on CDS bid-ask spreads across CDS premiums. Furthermore, the funding effect is stronger for CDS contracts on smaller and riskier firms, contracts with longer maturities, and non-centrally-cleared contracts. The effect also becomes stronger after Deutsche Bank exits the CDS market. Finally, we find similar results using European CDSs. Our experimental setting offers new economic insights on the quantification and mechanism of the funding liquidity effect.
\end{abstract}

Keywords: funding liquidity, CDS Big Bang, CDS Small Bang, standardization, central clearing JEL Classification: G11, G12, G13, G14, G18, G28 


\section{Introduction}

The effect of funding liquidity has been analyzed extensively in the theoretical literature, especially since the recent global financial crisis (e.g., Brunnermeier and Pedersen (2009), He and Krishnamurthy (2013), and Brunnermeier and Sannikov (2014), among others). On the empirical side, a number of studies have examined the link between funding liquidity constraints and market liquidity (e.g., Coughenour and Saad (2004), Comerton-Forde et al. (2010), Hameed, Kang, and Viswanathan (2010), Garleanu and Pedersen (2011), and Karolyi, Lee, and Van Dijk (2012)). These studies examine whether or not funding liquidity constraint has an adverse effect on market liquidity. As is clear in Brunnermeier and Pedersen (2009), funding liquidity, market liquidity, and asset prices are jointly determined in equilibrium, making it difficult to identify the effect of funding liquidity. However, for some issues, such as policy evaluations, it is crucial to isolate and quantify the funding liquidity effect.

In this paper, we exploit a quasi-experiment to not only quantify the effect of funding liquidity, but also examine the economic mechanism behind the funding effect. On April 8, 2009, a collection of trading convention changes was introduced into the CDS market, which is commonly referred to as the "CDS Big Bang." The purpose of these changes is to standardize CDS contracts. After the CDS Big Bang, North American CDS contracts trade with a fixed coupon set at either 100 basis points (bps) or 500 bps. The fixed coupon is typically chosen nearest to the spread at which the CDS contract is trading. The difference in the present value between the CDS spread and the fixed coupon over the life of the CDS contract is settled upfront. For example, an investor buying protection for a firm with a 5-year CDS spread of 150 bps will

pay $100 \mathrm{bps}$ running over five years and an upfront fee equivalent to the present value of $50 \mathrm{bps}$ over five years. The size of the upfront fee is larger if the credit spread is "further away" from the coupon rate. This upfront fee and its dependence on the credit spread level allow us to identify the cross-sectional effect of this funding requirement through diff-in-diff analyses. 
How large is this upfront fee in aggregate? In our main sample, the average size of the upfront fee is about $4.07 \%$ of the notional amount of CDS contracts. According to the Trade Information Warehouse (TIW) reports from the Depository Trust \& Clearing Corporation (DTCC), the gross notional value of single-name CDS trades executed between April and December 2009 is about $\$ 10$ trillion. In addition, Duffie, Scheicher, and Vuillemey (2015) estimate the ratio between net and gross notional amounts of single-name CDS to be around 7.6\%. Hence, the aggregate net notional amount of single-name CDS trades during this period is estimated to be about $\$ 0.76$ trillion. Excluding the upfront fees for all off-setting positions, the aggregate monthly upfront fee for these new trades is approximately 3.87 billion dollars. ${ }^{1}$ This funding requirement due to upfront payments is expected to have a considerable cross-sectional effect on market liquidity. Indeed, the liquidity effect from upfront payments was anticipated by practitioners before the implementation of the CDS Big Bang. ${ }^{2}$

We first hypothesize that, assuming standardization is liquidity enhancing, due to funding cost, liquidity improvement is smaller for contracts that require larger upfront fees. In other words, controlling for other effects, CDS bid-ask spreads are larger for contracts with larger upfront fees after the CDS Big Bang, which offers a unique setting to test the prediction in Brunnermeier and Pedersen (2009). ${ }^{3}$ Specifically, we regress five-year CDS bid-ask spreads on the interaction term between the upfront funding cost (based on the distance between the CDS spread and the fixed coupons) and a dummy variable that is 0 before the CDS Big Bang, and 1 afterwards. ${ }^{4}$ The coefficient of this interaction term is estimated to be $2.36(t=6.08)$, consistent with our hypothesis. What is the economic magnitude of this effect? Consider a CDS contract with a spread level of $300 \mathrm{bps}$ as an example. Our estimate implies that, for this contract, the upfront funding cost increases the bid-ask spread by $1.51 \mathrm{bps}$. Therefore, the result is also

\footnotetext{
${ }^{1}$ The estimate of 3.87 billion is equal to 0.76 trillion multiplied by $4.07 \%$ divided by 8 , where 8 is the number of months from April to December 2009.

${ }^{2}$ For instance, J.P. Morgan Worldwide Securities Services predicted in Credit Derivatives Standardization Initiatives 2009 that after the CDS Big Bang, liquidity is expected to increase more for CDS contracts whose spreads are closer to the fixed coupons (100 and $500 \mathrm{bps}$ ).

${ }^{3}$ We address the overall effect, which is a combination of the two opposing forces, the liquidity enhancing effect of standardization and the funding effect of upfront fee requirement, in the Section 6.

${ }^{4} \mathrm{We}$ also use a measure of upfront funding cost calculated by the ISDA CDS standard model and find similar results.
} 
economically important given that our sample median and mean of the bid-ask spreads are 5.30 and $9.61 \mathrm{bps}$, respectively.

Second, to shed light on the economic mechanism behind the funding effect, we also examine variations in the funding effect across firms. Our evidence suggests that the funding effect is stronger for CDS contracts on smaller and riskier reference entities. This is consistent with the prediction in Brunnermeier and Pedersen (2009) that the funding effect is stronger for riskier and less liquid securities. In addition, exploiting the monotonic relation between the size of upfront payments and the maturity of CDS contracts, we examine the funding effect on CDS contracts with different maturities. Our results indicate that the upfront funding effect is stronger for contracts with longer maturities, which is consistent with the prediction in Brunnermeier and Pedersen (2009) that a larger funding requirement leads to a larger reduction in market liquidity.

Third, to further examine the economic mechanism behind the effect of upfront funding cost, we analyze two major events in the CDS market after the CDS Big Bang. The first event is central clearing. In December 2009, eight months after the CDS Big Bang, ICE Clear Credit (ICECC) started to clear CDS trades. As noted in Section 2.1, central clearing can facilitate netting and mitigate the upfront funding effect. We analyze this mechanism through diff-in-diff regressions. Consistent with this prediction, our estimates suggest that, on average, central clearing reduces the effect of upfront funding cost on the bid-ask spread by around $0.6 \mathrm{bps}$. The second major event is the exit of Deutsche Bank from the single-name CDS market. Deutsche Bank, a major CDS dealer, decided to exit the single-name CDS market in late 2014 because "regulation had made the business less attractive". 5 This creates a major shock to the aggregate market making capacity in the CDS market. As shown in Brunnermeier and Pedersen (2009), the funding effect is stronger when traders' capital constraint is closer to being binding. Consistent with this prediction, our evidence suggests that the bid-ask spread becomes more sensitive to the upfront funding cost after Deutsche Bank's exit. Our estimate shows that, on average, the effect

\footnotetext{
${ }^{5}$ See, for example, Deutsche Bank Exits Credit Swaps Trades on Most Companies, Bloomberg November 17, 2014, https://www.bloomberg.com/news/articles/2014-11-17/deutsche-bank-exits-most-single-name-credit-default-swaptrading.
} 
of upfront funding cost on the bid-ask spread increases approximately by an additional 0.7 bps after Deutsche Bank's exit.

Fourth, as independent tests on entirely new datasets on European firms, we repeat our analysis on the funding cost effect using the CDS Small Bang, a similar collection of trading protocol changes for CDS contracts on European reference entities implemented on June 20, 2009. We examine the funding effect on European firms around the CDS Small Bang following the similar analyses based on the North American data. We find that, controlling for other effects, the bid-ask spread for European CDSs is larger when the upfront funding cost is larger. We also repeat the analyses on firms with different sizes and credit ratings, CDS with different maturities, central clearing, and the exit of Deutsche Bank. The results on European firms are consistent with the results using North American CDS data.

Finally, we perform a variety of robustness checks and further analyses that support our results. To account for potential confounding effects of unobserved shocks around the time of the CDS Big Bang, we conduct a triple difference analysis using samples from both North American and European CDS markets, taking advantage of the delayed implementation of the CDS Small Bang in Europe. We find that, after the CDS Big Bang but before the CDS Small Bang, the bidask spread becomes more sensitive to the upfront funding costs for North American CDS contracts, after controlling for the effect in the European sample. In addition, we conduct supplementary analyses on the CDS-bond basis and the volatility of CDS spreads and find that the absolute value of the CDS-bond basis and the CDS volatility are larger when the upfront funding cost is larger. Our results are also robust to different methods of sample construction.

Our paper contributes to the literature on the effects of funding liquidity and traders' capital constraints in financial markets. Important theoretical contributions include Grossman and Miller (1988), Shleifer and Vishny (1997), Basak and Croitoru (2000), Xiong (2001), Kyle and Xiong (2001), Gromb and Vayanos (2002), Brunnermeier and Pedersen (2009), He and Krishnamurthy (2013), and Brunnermeier and Sannikov (2014), among others. On the empirical side, funding liquidity effects have been analyzed in various contexts. For example, Chordia, Sarkar, and Subrahmanyam (2005) document that the common factors in the shocks to stock and 
bond market liquidity appear to be correlated with money flows. Karolyi, Lee, and Van Dijk (2012) find that the commonality in liquidity is greater in countries with and during times of high market volatility, especially after large market declines. Coughenour and Saad (2004) find that the liquidity of stocks handled by the same specialist firm displays excess co-movement. Comerton-Forde et al. (2010) find that the market liquidity of a stock decreases when its market maker holds large inventory or has suffered recent trading losses. Hameed, Kang, and Viswanathan (2010) find that negative market returns decrease stock liquidity. Several studies use major market events as exogenous shocks to the funding condition of financial intermediaries to examine their effects on market liquidity (e.g., Acharya, Schaefer, and Zhang (2015), Aragon and Strahan (2012), and Dick-Nielsen, Feldhutter, and Lando (2012)). ${ }^{6}$ These studies focus on whether or not the funding constraint has an adverse effect on market liquidity. The contribution of our paper is that our setup makes it possible to quantify the effect of funding liquidity, and to examine the economic mechanism behind the funding effect.

Our paper is also related to the analysis of standardization in the over-the-counter (OTC) derivative market. Oehmke and Zawadowski $(2015,2017)$ argue that one important role of the CDS market is to provide standardization to the bond market. Augustin et al. (2016) argue that standardization fosters aggregation of information and price discovery. Chen et al. (2011) document the effects of the CDS Big Bang on the standardization of products and trading conventions. Despite many benefits of standardization, derivatives end-users face higher costs because they are less likely to find a product that exactly matches their needs (e.g., Stulz (2010) and Duffie, Li, and Lubke (2010)). Our analysis highlights the mechanism through which standardization of CDS contracts affects market liquidity. The CDS Big Bang or Small Bang has been used to study the empty credit hypothesis (Danis (2017)), liquidity spillover from CDS to equity markets (Haas and Reynolds (2017)), and the effect on credit availability (Gunduz et al.

\footnotetext{
${ }^{6}$ More generally, Adrian, Etula, and Muir (2014) and He, Kelly, and Manela (2017) find that the capital constraints of financial intermediaries can help to price cross-sectional asset returns. Mitchell, Pedersen, and Pulvino (2007) and Mitchell and Pulvino (2012) document cases where arbitrage capital appears slow in exploiting opportunities.
} 
(2017)). However, none of these papers examines the cross-sectional effect of upfront payments induced by the CDS Big Bang, which is the focus of our paper.

Finally, our paper also adds to the large literature on the liquidity in the CDS market (e.g., Longstaff, Mithal, and Neis (2005), Tang and Yan (2007), Bongaerts, De Jong, and Driessen (2011), Qiu and Yu (2012), Shachar (2011), Chen, Cheng, and Wu (2013), and Loon and Zhong (2014)). See Augustin et al. (2016) for a recent survey on this literature.

\section{Institutional Background and Hypothesis Development}

\subsection{Institutional background}

To standardize CDS contracts, the International Swaps and Derivatives Association (ISDA) introduced a collection of contract and trading convention changes in the CDS market on April 8, 2009, known as the "CDS Big Bang". 7 The changes in the CDS Big Bang include fixed coupon rates and upfront payments, standard effective dates, determinations committees, and auction settlement changes. The relevant change for our study is trading with fixed coupons and upfront payments. Before the CDS Big Bang, a single-name CDS contract was traded at a coupon rate that set the contract value to zero on the inception day. After the trading convention change, however, North American CDS contracts trade with two fixed coupons of 100 and 500 bps. Since the CDS spread is typically not exactly equal to the fixed coupons, upfront payments are required for trading CDS contracts. ${ }^{8}$ Soon after the implementation of the CDS Big Bang, the ISDA published similar trading convention changes for European single-name CDS contracts on

\footnotetext{
${ }^{7}$ For more details, see Markit technical report, "The CDS Big Bang: Understanding the Changes to the Global CDS Contract and North American Conventions," March 13, 2009.

${ }^{8}$ In principle, one can avoid upfront payments by trading two contracts at the same time. For instance, if a CDS spread is $300 \mathrm{bps}$, one can take half a position in the 100-coupon contract and half a position in the 500-coupon one, so that the upfront payments of the two contracts cancel out each other. This is similar to the process known as "portfolio re-couponing", which modifies legacy CDS positions into 100 and 500 fixed coupon positions. However, this strategy is usually infeasible, because many contracts have only one coupon traded. For those with dual coupons, liquidity is typically concentrated in one contract, making it expensive to trade the less liquid one.
} 
June 20, 2009, known as the "CDS Small Bang", after which European CDS contracts trade with four fixed coupons of 25, 100, 500 and 1000 bps. $^{9}$

The intention of the trading convention change is to standardize CDS contracts to facilitate trade compression and central clearing. However, this trading convention change also induces an upfront payment, whose size depends on the CDS spread level. Suppose, for example, that a contract has a CDS spread of 150 bps. That is, the "breakeven" coupon rate is 150 bpsthe contract is worth zero on the inception day if the coupon rate is set to be $150 \mathrm{bps}$. After the CDS Big Bang, however, the coupon rate can only be either 100 or 500 bps. Suppose that the coupon rate is set to be $100 \mathrm{bps}$. Since this coupon rate is $50 \mathrm{bps}$ less than the breakeven rate (which is $150 \mathrm{bps}$ ), the protection buyer needs to compensate the seller by paying an upfront fee that is equal to the present value of 50 bps per year during the life of the CDS contract. Alternatively, suppose that the coupon rate is set to be 500 bps. Since this coupon rate is 350 bps more than the breakeven rate (which is $150 \mathrm{bps}$ ), the protection seller needs to pay an upfront fee that is equal to the present value of $350 \mathrm{bps}$ per year during the life of the CDS contract. ${ }^{10}$ In summary, the CDS Big Bang induces upfront fees. The size of the fee depends on the CDS spread level: it is larger if the CDS spread is "further away" from the coupon rate.

Since there were margin requirements for CDS trading even before the CDS Big Bang, the funding cost induced by upfront payments is in addition to the funding cost for the margins for CDS trades. ${ }^{11}$ Before the CDS Big Bang, for a trade between a dealer and a customer, an initial margin is generally required at the inception for the customer but not the dealer (although proposed regulatory reforms will also require dealers to post initial margins for inter-dealer trades). Moreover, variation margins are posted by both parties and adjusted over time according to their collateral agreement when the mark-to-market value of the CDS contract changes. After the CDS Big Bang, on the inception day of a trade, a trader pays the upfront fee and its

\footnotetext{
${ }^{9}$ For more details, see Markit technical report, "CDS Small Bang: Understanding the Global Contract and European Convention Changes," July 20, 2009.

${ }^{10}$ Naturally, in practice, the coupon is typically chosen to minimize the upfront fee. Hence, in the above example of a contract with a CDS spread of $150 \mathrm{bps}$, the coupon rate is typically chosen to be $100 \mathrm{bps}$.

11 The details for the margin requirements for CDS trades are described in Duffie, Scheicher, and Vuillemey (2015).
} 
counterparty typically posts the received fee as the variation margin. This upfront payment is an extra funding requirement in addition to the initial margin. ${ }^{12}$

It is also important to point out that the funding costs also depend on trade size or traders' aggregate position. If trade size or aggregate exposure for traders decreases, then there might not be really an increase in the aggregate funding cost after the CDS Big Bang. According to "CDS Market Summary: Market Risk Transaction Activity”, ISDA research notes 2013, the aggregate level of CDS gross notional outstanding has indeed decreased since the global financial crisis. However, the ISDA research notes also show that the decrease has been mostly caused by portfolio compression (also called trade tear-ups), which eliminates economically redundant trades and reduces notional outstanding. ${ }^{13}$ The ISDA research notes suggest that a better way to understand the CDS market dynamics is to look at trading activities in the market, as opposed to transactions outstanding at a point in time. According to the data shown in the ISDA research notes, there are only slight decreases in the gross notional of new market risk transaction activities and the average trade size of single-name CDSs. ${ }^{14}$ Given that the upfront fees went up from zero to about $4 \%$ for single-name CDSs around the CDS Big Bang, it is reasonable to expect a funding cost shock around the CDS Big Bang. Moreover, after the CDS Big Bang, there is a non-monotonic relationship around the fixed 100 or 500 bps coupons. Our analysis is based on this non-monotonic relationship.

After the global financial crisis, the US Congress passed the Dodd-Frank Wall Street Reform and Consumer Protection Act, which mandates central counterparty (CCP) clearing for eligible OTC derivatives including CDSs. ICECC began central clearing services for singlename CDSs in December 2009. Over time, more CDS contracts became eligible for central clearing. By the end of our sample period, October 2016, CDS contracts for 243 North American firms had been centrally cleared at ICECC. For centrally cleared transactions, the central

\footnotetext{
${ }^{12}$ For more details on the funding requirement changes induced by the CDS Big Bang, see, e.g., The Bond-CDS Funding Basis (Europe Credit Derivatives Research, JP Morgan September 2009).

${ }^{13}$ The purpose of portfolio compression is to decrease CDS gross notional amounts outstanding while not changing the economic details of a party's net position.

${ }^{14}$ The DTCC measures market risk transaction activity as transactions that change the risk position between two parties, which include new trades between two parties, a termination of an existing transaction, or the assignment of an existing transaction to a third party.
} 
counterparty clearing house stands between traders and serves as the sole counterparty for all traders. This has implications on the treatment of upfront payments.

Before central clearing, suppose that a dealer sells a protection on a reference entity to investor A, and, to offset this exposure, buys a protection on the same reference entity from investor B. In this case, the dealer needs to pay an upfront fee for one position, and receives an upfront fee of similar size for the other. Suppose, then, that the dealer receives an upfront fee from A, and pays an upfront fee to B. Without central clearing, although these two offsetting payments are similar in size, the dealer cannot net them. ${ }^{15}$ Specifically, for the trade between the dealer and A, the mark-to-market value of the CDS contract for investor A is the size of the upfront fee. Hence, on the one hand, the dealer needs to post the fee from A as collateral for this trade. ${ }^{16}$ On the other hand, the dealer has to finance the upfront fee for the trade with investor B. After central clearing, for centrally cleared transactions, the CCP serves as the sole counterparty for all parties. In the above-mentioned example, the dealer has two offsetting positions with two different investors (A and $\mathrm{B}$ ). If both positions are cleared at the same $\mathrm{CCP}$, the dealer now effectively has the two offsetting positions with the same counterparty. ${ }^{17}$ Hence, the dealer can net the two offsetting upfront fees.

\subsection{Empirical hypotheses}

The CDS Big Bang is expected to have at least two opposing effects on market liquidity. First, the standardization of CDS contracts is expected to enhance market liquidity. Second, the

\footnotetext{
${ }^{15}$ A practice known as rehypothecation may alleviate this netting issue. It allows the receiver of collateral (usually a dealer) to use the collateral for her own purposes upon the permission of the payer of the collateral. Since the onset of the global financial crisis, however, this practice has encountered difficulties. The Dodd-Frank Act put further restrictions on rehypothecation for derivatives.

${ }^{16}$ If there is a collateral agreement between two parties of a trade, the party who receives an upfront fee is not entitled to retain the payment, but must post the payment as collateral to the payer. According to the 2009 ISDA margin survey, 66 percent of net credit exposure of OTC derivatives is covered by collateral. Collateral is usually held either by dealers' internal custody service or by a third agent upon the request of the counterparty. In either case, once the upfront fee is transferred to a custody account, neither party can use the payment for their own purposes. In other words, collateral agreements freeze upfront fees for both parties. After the inception of a trade, additional collateral may be called or released when the mark-to-market value of the trade changes. The collateral from the upfront fee is gradually released over time when the trade approaches maturity. For more details on collateral requirements in practice, see The Standard Credit Support Annex, ISDA, 2011.

${ }^{17}$ As noted in Duffie and Zhu (2011), central clearing cannot fully address this netting issue if there are multiple clearing houses.
} 
upfront funding cost arising from the fixed coupons is expected to reduce market liquidity of firms with different levels of CDS spreads (cross-sectional effect). Our hypotheses focus on the second aspect, predicting that the effect of upfront funding cost on the bid-ask spread is different across CDS spreads. We will discuss the overall effect, which is determined by the tradeoff between these two opposite forces, in Section 6.5. In the following, we develop four hypotheses related to the cross-sectional effect across CDS spreads.

Hypothesis 1: Assuming standardization is liquidity enhancing, due to funding cost, the liquidity improvement is smaller for contracts with larger upfront fees. That is, controlling for other effects, CDS bid-ask spreads are larger for contracts with larger upfront fees after the CDS Big Bang.

As shown in the testable prediction 2 of Brunnermeier and Pedersen (2009, p. 2227), funding liquidity shocks reduce market liquidity. This prediction can be tested by examining the cross-sectional relation between the upfront fee and the bid-ask spread. The CDS Big Bang induces upfront fees which depend on the credit spread level. This allows us to identify the effect of this funding requirement through diff-in-diff analyses. For contracts with larger upfront fees, the effect is expected to be larger.

Intuitively, upfront fees are similar to margins. Although important for standardization, the upfront payment induced by the CDS Big Bang also requires capital for trading. As modeled in Brunnermeier and Pedersen (2009), market illiquidity of an asset is equal to the product of its margin and traders' cost of funding. This suggests that market illiquidity of a CDS contract is also linked to the product of its upfront fee and traders' cost of funding. Specifically, the upfront fees increase the cost of market making for dealers, because they have to incur extra funding costs when they take offsetting positions. ${ }^{18}$ As explained in the institutional background (Section

\footnotetext{
${ }^{18}$ In addition, the upfront fees reduce traders' willingness to trade, which also increase the cost of market makers. As in Garleanu and Pedersen (2011) and Shen, Yan, and Zhang (2014), capital-constrained investors are reluctant to trade assets that are capital intensive. For investors, the benefit from receiving the upfront fee is typically smaller than the cost of paying it. The trader who receives the upfront fee has to post it as collateral, and so earns a return that is typically lower than her cost of funding. Hence, the upfront payment reduces market activities, making it difficult for dealers to make the market and leading to higher bid-ask spreads.
} 
2.1), if a dealer takes two offsetting positions with two different customers, the dealer typically cannot net the two upfront payments without central clearing, i.e., she cannot use the received fee from one customer to pay the other customer. Instead, she has to post the received fee as collateral, and incur the funding cost to pay the other fee. Finally, as also theoretically formulated in Andersen, Duffie, and Song (2017), funding the upfront payments is costly to dealers, which leads to higher bid-ask spreads.

Hypothesis 2: Ceteris paribus, the effect of upfront funding cost on the CDS bid-ask spread is stronger for riskier and less liquid CDSs.

The funding cost effect is also expected to have a differential effect across firms. Brunnermeier and Pedersen (2009) predict that the funding effect is stronger for riskier and less liquid assets. This prediction provides a test for the additional implication of the funding effect. The market liquidity of all assets depends on traders' funding liquidity. When there is a negative shock to traders' funding, traders reduce trading by a greater amount on riskier and less liquid assets, and therefore there is a greater reduction in market liquidity for riskier and less liquid assets. In our context, to the extent that CDS contracts with lower credit ratings and smaller reference entities are riskier and less liquid, we predict that the funding effect to be stronger for CDS contracts on riskier and smaller reference entities.

Hypothesis 3: Ceteris paribus, the upfront fee is larger for CDS contracts with longer maturities, and so the funding effect on the CDS bid-ask spread is stronger for contracts with longer maturities.

Since an upfront payment is the present value of risky payments that is equal to the difference between the CDS spread and the fixed coupon during the life of a CDS contract, the size of the upfront payment also depends on the maturity of the contract. Because the firm characteristics and contract specifications are identical across contracts with different maturities on a reference entity, the size of the upfront payment increases monotonically with contract 
maturities. This provides another setting to test the prediction 2 of Brunnermeier and Pedersen (2009) that a larger funding requirement leads to a greater reduction in market liquidity.

Hypothesis 4: Ceteris paribus, the effect of upfront funding cost on the CDS bid-ask spread is smaller for centrally cleared transactions.

Central clearing can alleviate the effect of upfront funding cost through more efficient netting. Specifically, for centrally cleared transactions, a CCP serves as the sole counterparty for all parties. This allows a higher degree of netting benefits across trades. For instance, as explained in the institutional background (Section 2.1), where the dealer has two offsetting positions with two different investors, if both positions are cleared at the same $\mathrm{CCP}$, the dealer now effectively has two offsetting positions with the same counterparty, namely the CCP. Hence, the dealer can net the two offsetting upfront fees. Central clearing frees up capital, and thus dealers are further away from their funding constraints. Therefore, central clearing provides a nice setting to test the prediction 3 of Brunnermeier and Pedersen (2009) that, when traders are further from their constraints, the funding effect is smaller.

\section{Data and Upfront Funding Cost Measures}

\subsection{Data and summary statistics}

We obtain daily bid and ask quotes for CDS contracts on North American companies from two sources. Our main analysis is based on the data from Credit Market Analysis Ltd. (CMA) via Datastream, which we will refer to as the "North American CMA sample." In the main analyses, we will focus on the 5-year CDS contracts since they are the most liquid and most widely-traded contracts. The sample consists of 634 companies from January 1, 2004 to September 30, 2010. ${ }^{19}$ Hence, this sample covers about five years before and one and a half years after the CDS Big Bang. Our second CDS data source is the Liquidity Report from the CDS Pricing Data of Markit Group Ltd., and we will refer to it as the "North American Markit sample." Its 5-year CDS

\footnotetext{
${ }^{19}$ From October 1, 2010, CMA data are not available without a separate license.
} 
contracts cover 765 North American companies (out of which 319 are also in our CMA sample) from April 1, 2010 to October 19, 2016. That is, the Markit sample only covers the post-BigBang period. Nevertheless, it is a useful complement to our CMA data.

To analyze the CDS Small Bang, we also obtain similar CDS data for European companies from CMA and Markit. The European CMA sample covers 423 companies from January 1, 2004 to September 30, 2010. The European Markit sample covers 547 companies from April 1, 2010 to October 19, 2016.

We apply the following filters to the CDS bid and ask quotes for all samples. We remove observations where the bid quote is greater than or equal to the ask quote, or the quote is indicated as "derived" rather than "observed." To improve the identification of the funding effect, we also remove the observations if the mid-point of bid and ask quotes is greater than 750 bps for the North American samples and 1000 bps for the European samples. ${ }^{20}$ After applying these filters, the North American CMA and Markit samples consist of 633,977 (620 firms) and 659,618 (728 firms) daily observations, respectively. The European CMA and Markit samples consist of 429,455 (401 firms) and 467,682 (540 firms) daily observations, respectively.

Table 1 reports the summary statistics. Each variable is pooled over time and across firms. Panel A shows that the mean and median of the bid-ask spread in the North American CMA sample are 9.61 and 5.30 bps, respectively. In the North American Markit sample in Panel B, the mean and median are slightly higher, at 12.39 and 10.00 bps, respectively. As shown in Panel C and D, the bid-ask spread in the European samples has very similar mean and median values as the North American samples.

The credit ratings of the reference entities in our samples are mostly between A and B, according to S\&P long-term issuer credit ratings. The mean and median CDS spreads are 137

\footnotetext{
${ }^{20}$ This is because before the CDS Big Bang, some CDS contracts on distressed firms were already traded with a fixed coupon of $500 \mathrm{bps}$ and upfront payments (The CDS Big Bang: Understanding the Changes to the Global CDS Contract and North American Conventions, Markit 2009). For example, trading CDS on GE capital (CDS spread $710 \mathrm{bps}$ ) required upfront payment $\$ 850,000$ and a fixed coupon of $500 \mathrm{bps}$ in March 2009 . The cutoff of $750 \mathrm{bps}$ for the North American samples is chosen to mitigate the impact of distressed firms. This filter removes about $5.5 \%$ of total observations in the CMA sample and 5\% in the Markit sample. In Section 6, we show that our results are robust if the cutoff is chosen to be $1000 \mathrm{bps}$, or if CDS spreads are winsorized at 99\%. Since European CDSs have a fixed coupon of $1000 \mathrm{bps}$, we choose a cutoff of $1000 \mathrm{bps}$ for the European samples.
} 
and 71 bps, in our North American CMA sample, and are 155 and 102 bps in our North American Markit sample, respectively. Similar to the North American samples, the mean and median CDS spreads are 114 and 60 bps, in our European CMA sample, and are 157 and 105 bps in our European Markit sample, respectively.

As control variables, we obtain daily close values of the CBOE volatility index from Datastream, reference entities' stock returns, trading volume, and bid-ask spreads from CRSP, assets and liabilities from Compustat, transaction prices of bonds issued by the reference entities from TRACE, and bond characteristics from Mergent Fixed Income Securities Database (FISD). We construct two bond market liquidity measures. The first is the Amihud (2002) measure, defined as $1 / N \sum_{i=1}^{N}\left|r_{i}\right| / v_{i}$, where $N$ is the number of trades within a given day, $r_{i}$ and $v_{i}$ are the percentage price change and the dollar volume of the $i$ th trade, respectively. If a firm has multiple bonds, we aggregate the Amihud measures of all bonds issued by the same firm (identified by its 6-digit CUSIP number) by averaging their daily values. The second measure is the trading volume aggregated across daily trading volumes of all bonds issued by the same firm.

\subsection{Upfront funding cost measures}

The upfront funding cost has two components: the upfront fee size and the funding cost of each unit of payment. As illustrated in earlier examples, after the CDS Big Bang, the size of the upfront fee is determined by the distance between the CDS spread and the coupon rate. In our CMA sample, we cannot directly observe the upfront fee size or the coupon rate, but can infer them from the CDS spread. After the CDS Big Bang, when broker-dealers provide their quotes to CMA, they follow a standard procedure to convert the coupon rate and the upfront fee into a CDS spread. ${ }^{21}$ We can infer the coupon rate (i.e., 100 or 500 bps) since it is usually chosen to be closer to the CDS spread. ${ }^{22}$ Hence, for each CDS contract $i$ on day $t$, we construct a variable $D I S_{i t}$

$$
D I S_{i t}=\min \left(\left|S_{i t}-100\right|,\left|S_{i t}-500\right|\right) \text {, }
$$

\footnotetext{
21 The ISDA CDS Standard Model is used to convert coupon rates and upfront fees into the CDS spread. The details of the model are available from http://www.cdsmodel.com/cdsmodel/.

${ }^{22}$ For example, according to our Markit sample, where the coupon rate is directly observable, the "primary coupon rate" is chosen to be the one that is closer to the CDS spread for about $92 \%$ of the observations.
} 
where $S_{i t}$ is the CDS spread of contract $i$ on day $t$. That is, DIS is the minimum distance between the CDS spread and the two possible coupon rates. For a given maturity of CDS contracts, DIS can be used as a proxy for the upfront fee size. After the CDS Big Bang, for CDS contracts with the same maturity, the size of the upfront fee is approximately linear in $D I S .^{23}$ The higher the $D I S$, the larger the upfront fee.

To measure the price of funding, we follow Garleanu and Pedersen (2011) and use the 3month Libor-OIS spread, which is the 3-month Libor rate minus the 3-month overnight indexed swap (OIS) rate. The Libor rate is the uncollateralized borrowing rate of large banks and the OIS rate is often considered the risk-free rate. Hence, this spread is a proxy for the price of funding for large institutional investors. From Bloomberg, we obtain daily close values of Libor-OIS spreads, which have significant variations in our sample period, ranging from under 5 bps to over 250 bps during the recent financial crisis.

The upfront funding cost can be measured as:

$$
F_{i t}=D I S_{i t} \times \operatorname{LOIS}_{t}
$$

where LOIS $_{t}$ is the 3-month Libor-OIS spread on day $t$. Therefore, $F_{i t}$ reflects the upfront funding cost for trading CDS contract $i$ on day $t$, but only for the post-CDS-Big-Bang sample.

The measure based on DIS is intuitive but not a direct measure of upfront fees. We also consider an alternative and more sophisticated measure. Following the industrial practice in the CDS market, we employ the ISDA CDS standard model to convert the distance between the coupon rate and the CDS spread into the upfront fee. ${ }^{24}$ Specifically, using our North American CMA sample, we calculate the two possible upfront fees for the two coupon rates (100 bps and $500 \mathrm{bps}$ ) and choose the smaller one as our estimated upfront fee, Fee $e_{i t}^{I S D A}$. The upfront funding cost is then measured as

$$
F_{i t}^{I S D A}=F e e_{i t}^{I S D A} \times L O I S_{t}
$$

\footnotetext{
${ }^{23}$ The nonlinearity is caused by the possibility of default of the reference entity, but the effect is minor for our sample, where the credit spread is below 750 bps.

${ }^{24}$ We use the function "JpmcdsCdsoneUpfrontCharge" to compute the upfront fee from the CDS spread, coupon rate, and the term structure of the LIBOR rates. Details of this function and the model can be found at http://www.cdsmodel.com/cdsmodel/.
} 
Finally, in our Markit sample, we can observe the actual size of the upfront fee. As shown in Panel B of Table 2, the average upfront fee size, Fee, is $4.07 \%$ of the notional amount of the CDS contract. The upfront funding cost is measured as

$$
F_{i t}^{\text {Markit }}=\text { Fee }_{i t} \times \text { LOIS }_{t}
$$

\section{Analyses Using the CDS Big Bang}

In this section, we exploit the CDS Big Bang to test the four hypotheses developed in Section 2 using the North American samples.

\subsection{The upfront funding cost effect on bid-ask spreads around the CDS Big Bang}

Hypothesis 1 argues that, controlling for other effects, CDS bid-ask spreads are larger for contracts with larger upfront fees after the CDS Big Bang. To test this implication, we first run two panel regressions of CDS bid-ask spreads on $F$, one for the pre-Big-Bang sample and the other for the post-Big-Bang one. All our regressions include firm-fixed effects and monthly timefixed effects. ${ }^{25}$ The results are reported in Panel A of Table 2. As shown in columns (1) and (2), the coefficient of $F$ is 0.59 ( $t=5.46)$ in the pre-Big-Bang sample, and it increases substantially to $2.89(t=7.92)$ in the post-Big-Bang sample. ${ }^{26}$ The difference between these two coefficients identifies the funding effect from the CDS Big Bang. This is formally estimated in the regression in column (3), which is based on the entire sample, and includes the interaction term $F \times B B$, where $B B$ is a dummy variable that is 0 before the CDS Big Bang and 1 afterwards. The estimate of the interaction coefficient is $2.36(t=6.08)$, indicating that the CDS bid-ask spread becomes more correlated with $F$ after the CDS Big Bang, which is consistent with Hypothesis 1. For a CDS contract with a spread of $300 \mathrm{bps}$, for example, this estimate implies that when the Libor-

\footnotetext{
25 The aggregate notional value of the CDS market decreases from over \$60 trillion in 2007 to about $\$ 30$ trillion at the end of 2010. Our identification strategy relies on cross-sectional variations in upfront fees. Hence, it is important to include time-fixed effects to control for those unobservable aggregate shocks. As robustness checks, we also repeat our analysis using quarterly and weekly time-fixed effects. The results remain very similar.

${ }^{26}$ Note that $F$ is the product of the upfront payment and the Libor-OIS spread which is correlated with the bid-ask spread. Hence, its coefficient needs more careful discussion. We will designate Section 6.3 to provide more elaborated discussion of its coefficient.
} 
OIS spread is 32 bps (our sample mean), the upfront funding cost increases the bid-ask spread of this CDS contract by 1.51 bps. This is sizeable, as the mean and median of the bid-ask spreads in our sample are 9.6 and $5.3 \mathrm{bps}$, respectively.

In the previous analysis, the upfront fee is proxied by $D I S$, the distance between the coupon rate and the CDS spread since, for contracts with a given maturity, the fee is approximately linear in this distance. We repeat our earlier diff-in-diff analyses using our estimated upfront funding cost $F^{I S D A}$. The results, reported in columns (4)-(6) of Panel A of Table 2, are very similar to those in columns (1)-(3). For example, in column (6), the interaction term $F^{I S D A} \times B B$ is $0.53(t=5.66)$. This is consistent with the evidence in column (3) that the upfront funding cost has a differential effect on the bid-ask spread. In fact, since the estimated upfront fee $F e e^{I S D A}$ is mostly proportional to our earlier upfront fee measure DIS, the interaction coefficients in columns (4)-(6) are mostly proportional to those in columns (1)-(3). Given the similarity of the results based on DIS and Fee $e^{I S D A}$, we only report results based on upfront fees measured by DIS in the later sections.

Finally, we conduct placebo tests by using fictitious dates for the CDS Big Bang and repeat the above diff-in-diff tests. Specifically, we set two fictitious dates for the CDS Big Bang: October 8, 2008 (6 months before the actual date) and October 8, 2009 (6 months after the actual date). We then rerun the above diff-in-diff tests using one year of data around the two dates. In the first test, the sample is from April 8, 2008 to April 7, 2009. Since this entire sample period is before the policy change, we expect the interaction coefficient to be insignificant. Similarly, since the entire sample period in the second test (from April 8, 2009 to April 7, 2010) is after the policy change, we expect the interaction coefficient to be insignificant as well. Indeed, as shown in columns (1) and (2) of Panel B of Table 2, the estimates of the interaction coefficient are -0.31 $(t=1.49)$ and $0.32(t=0.16)$ for the two placebo tests. As a contrast, we also repeat our analysis using one year of data around the actual date for the CDS Big Bang. As shown in column (3), in sharp contrast to the two placebo tests, the interaction coefficient is $1.86(t=6.95)$. In columns (4)-(6), we show that the results are similar when the upfront fee is calculated by the ISDA CDS 
standard model. The placebo tests provide support that our main empirical results are indeed attributed to the implementation of the CDS Big Bang.

\subsection{Effect of upfront funding cost for firms with different ratings and sizes}

Our hypothesis 2 predicts that the funding effect should be stronger for CDS contracts on smaller and riskier reference entities. To test this hypothesis, we construct a dummy variable Small, which is 1 if the reference entity's asset value is below the median, and 0 otherwise. Similarly, we define a dummy variable Speculative, which is 1 if the reference entity's credit rating is below BBB, and 0 otherwise.

We then rerun the diff-in-diff regression in Table 2 with an additional term $F \times B B \times S m a l l$, and report the results in Table 3. As shown in column (1), the coefficient of this term is 1.34 $(t=2.63)$, suggesting that the funding effect is stronger for CDS contracts on smaller entities. Note that the coefficient for $F \times B B$ is 1.64 ( $t=3.44$ ), implying that the funding effect for CDS contracts on smaller reference entities is around $80 \%(\approx 1.34 / 1.64)$ stronger. Similarly, in column (2), the coefficient for $F \times B B \times$ Speculative is 1.33 ( $t=2.02)$ and the coefficient for $F \times B B$ is 1.91 $(t=4.58)$, implying that the funding effect for CDS contracts on entities with speculative ratings is around $70 \%(\approx 1.33 / 1.91)$ stronger. Overall, our evidence is consistent with the prediction in Brunnermeier and Pedersen (2009) that the funding effect is stronger for riskier or less liquid securities.

\subsection{Effect of upfront funding cost and CDS maturities}

In this subsection, we analyze CDS contracts with different maturities to provide further insights on the effect of upfront funding cost on market liquidity. Specifically, we collect data of 1-year, 3-year, 7-year and 10-year CDS contracts from Datastream, and apply the same filters as those in Section 3.1. We then repeat our diff-in-diff analysis for each maturity, and the results are summarized in Table 4. Column (1) reports the results based on the 1-year CDS contracts. Due to the small sample size (there are only 34 reference entities), the interaction coefficient is statistically insignificantly different from zero. Column (2) reports the results based on the 3-year 
CDS contracts. The coefficient of the interaction term $F \times B B$ is 2.67 ( $t=1.84)$, which is close to the estimate based on the 5-year contracts in column (3) of Panel A of Table 2. The results of similar regressions based on the 7-year and 10-year contracts are reported in columns (3) and (4). The coefficient of the interaction term $F \times B B$ is $3.92(t=2.82)$ and $4.16(t=2.16)$, respectively.

In column (5), we conduct a more rigorous analysis using all maturities. We consider a triple interaction $F \times B B \times$ Maturity where Maturity is the maturity of CDS contracts in years. We expect the triple interaction term to be positive. The coefficient of the triple interaction is 0.93 and statistically significant $(t=6.68)$. Consistent with Hypothesis 3, our evidence suggests that the upfront funding effect is stronger for contracts with longer maturities.

\subsection{Central clearing}

Central clearing is one of the main reasons for the standardization of CDS contracts. With central clearing, CDS traders only face a single counterparty: the CCP. Hence, if a CDS trader has multiple positions with the same CCP, she can effectively net her positions. This netting benefit can be large for CDS dealers, since they often have significant offsetting positions. Hence, central clearing can mitigate the upfront funding effect, as stated in Hypothesis 4. This economic mechanism is analyzed in the current section.

ICE Clear Credit (ICECC) started to clear single-name CDS contracts in December 2009, which is about 8 months after the CDS Big Bang. We obtain the initial dates for central clearing for firms in our sample from the historical circulars issued by ICECC from their official website (https://www.theice.com/clear-credit/circulars). ${ }^{27}$ Since our North American CMA sample ends in September 2010, it has limited coverage of central clearing. Our North American Markit sample, which ends in October 2016, has better coverage of central clearing. To avoid the confounding effect of the Deutsche Bank's exit in the CDS market around the end of 2014, we choose the sample period from April 1, 2010 to September 14, 2014. To analyze the influence of central clearing on the upfront funding effect, we define a dummy variable $C l e a r_{i, t}$, which is

\footnotetext{
${ }^{27}$ For those firms whose circulars are no longer available, we use the historical initial clearing dates from www.theice.com/publicdocs/ice_trust/ICE_Trust_Contract_Roster.xls.
} 
equal to 1 if the date is later than the initial clearing date $t$ for a CDS contract $i, 0$ otherwise. The upfront funding cost $F^{\text {Markit }}$ in our Markit sample is defined in equation (4). The effect of central clearing can be estimated by diff-in-diff tests. Specifically, we regress Bid-ask spread on the interaction term $F^{\text {Markit }} \times$ Clear and report the results in Table 5. In column (1), the estimate of the interaction term coefficient is $-0.41(t=2.46)$. This implies that, consistent with our hypothesis, our evidence suggests that central clearing mitigates the negative effect of upfront funding cost on bid-ask spreads. ${ }^{28}$

We note that one should interpret this result with caution because CDS contracts are, of course, not randomly selected for central clearing. One potential concern is that a contract's probability of being selected for central clearing somehow depends on the sensitivity of its market liquidity with respect to the upfront funding cost.

To partially address this concern, we create a subsample in which all the CDS contracts initiated central clearing during our sample period. That is, we exclude contracts that started central clearing before our sample starts, and those that still have not started central clearing at the end of our sample. This subsample covers CDS contracts on 109 firms. By focusing on this subsample where all contracts are selected at some point in time, we only need to be concerned that the timing of the selection depends on the sensitivity of market liquidity with respect to the upfront funding cost. This helps to alleviate some concern about the selection issue.

We run the same regression on this subsample and report the results in column (2). It shows that the effect remains very similar, and the interaction coefficient is $-0.69(t=3.4)$. The economic effect is also quantitatively important. For example, the average of $F C$ is 0.81 bps in our sample period. Hence, our estimate implies that, on average, due to the improvement in netting, central clearing reduces the bid-ask spread by around 0.6 bps $(=0.81 \times 0.69)$.

\footnotetext{
${ }^{28}$ Our goal is to test how and if central clearing influences the effect from funding liquidity shocks, which is identified from the diff-in-diff regression. To evaluate the overall effect of central clearing on market liquidity (which may or may not be driven by the funding liquidity effect), we run this regression without interaction terms. The coefficient for the dummy variable Clear is $-0.61(t=3.59)$, suggesting that central clearing reduces bid-ask spreads. This is consistent with the evidence in the literature, e.g., Loon and Zhong (2014). For brevity, the regression results without interaction terms are not presented in the paper.
} 
In sum, we find that central clearing can help to partially alleviate the funding cost effect, which is consistent with Hypothesis 4. This finding also indicates the importance of implementing central clearing after the standardization of CDS contracts.

\subsection{Exit of Deutsche Bank from the CDS market}

In late 2014, Deutsche Bank, a major CDS dealer, decided to exit the single-name CDS market because "regulation had made the business less attractive", creating a major shock to the aggregate market making capacity in this market. This shock offers a further test of the economic mechanism of the funding effect. As shown in Brunnermeier and Pedersen (2009), the funding effect is stronger when traders are closer to their capital constraints. The exit of Deutsche Bank reduces dealers' aggregate market-making capacity and thus dealers are closer to their funding constraints. Hence, we expect that the funding effect should be stronger after the exit of Deutsche Bank. It is worth noting that this event is after the sample period of our CMA sample, which is from 2004 to 2010 . Hence, this event offers yet another independent opportunity to test our hypotheses.

Deutsche Bank's exit from the CDS market has been a gradual process. Although Deutsche Bank's exit was reported in the media in November 17, 2014, the bank reportedly sold a portfolio of CDSs with a notional value of nearly $\$ 250$ billion, which is "around 5-10\% of a large dealer's total CDS book," to Citibank in September 2014 ${ }^{29}$ Hence, we consider 2 different event dates, September 15, 2014 and November 17, 2014. Specifically, we define a time dummy variable, $D B$, which is equal to 1 after the exit event and 0 otherwise. Since central clearing of CDS contracts started in December 2009, we also control for the effect of central clearing by including an interaction term $F^{\text {Markit }} \times$ Clear.

We regress the bid-ask spread on the interaction term $F^{\text {Markit }} \times D B$, and the results are reported in Table 6. As shown in column (1), where the exit event time is set to be September 15, 2014, the interaction coefficient is $0.83(t=3.33)$. This is consistent with our prediction that the

\footnotetext{
${ }^{29}$ See the report by Risk.net at https://www.risk.net/derivatives/credit-derivatives/2388970/citi-buys-250bndeutsche-bank-single-name-cds-portfolio.
} 
exit of Deutsche Bank from the CDS market reduces the aggregate market making capital, and hence the market liquidity becomes more sensitive to the upfront funding cost. In our sample, the average of $F^{\text {Markit }}$ is $0.81 \mathrm{bps}$, and hence our estimate implies that, on average, the Deutsche Bank exit increases the bid-ask spread by $0.7 \mathrm{bps}(=0.81 \times 0.83)$. Our results are not sensitive to the choice of the exit time. For example, column (2) reports the regression results when the exit date is set to be November 17, 2014. The interaction coefficient is similar in both economic magnitude and statistical significance.

\section{Analyses Using the CDS Small Bang}

In this section, we conduct further analyses on the funding effect using the CDS Small Bang based on similar methods as in Section 4.

\subsection{The upfront funding cost effect on bid-ask spreads around the CDS Small Bang}

As noted in Section 2.1, on June 20, 2009, about two months after the CDS Big Bang, similar trading protocol changes took place for European CDS contracts. This is commonly referred to as the "CDS Small Bang." Since the CDS Small Bang, the coupons for European single-name corporate CDS contracts have been restricted to be $25,100,500$, and $1000 \mathrm{bps}^{30}$ This event offers a chance for additional tests of our hypotheses in entirely new samples.

We define a time dummy variable $S B$ that equals 1 after June 20, 2009, otherwise 0 . The construction of the upfront funding cost $F$ is similar to that in (2), with two adjustments. The first is that DIS is now the minimum distance of the CDS spread to the four fixed coupons, 25,100 , 500, and 1000. The second adjustment is that the price of funding is now measured by LOIS Euro, the 3-month Euro Libor rate minus the 3-month Euro OIS rate.

\footnotetext{
${ }^{30}$ For more details, see Markit technical note, CDS Small Bang: Understanding the Global Contract and European Convention Changes, July 20, 2009. Two more coupons, 300 and $750 \mathrm{bps}$, have been implemented to allow more flexibility in re-couponing legacy trades.
} 
We run the same diff-in-diff regressions as those in Panel A of Table 2 based on the European CMA sample. The results are presented in Panel A of Table 7. In column (1), the coefficient for the interaction term $F \times S B$ is 3.61 ( $t=3.48)$. This provides additional supporting evidence to Hypothesis 1. That is, controlling for other effects, CDS bid-ask spreads are larger for contracts with larger upfront fees after the trading protocol changes took effect for European firms. In column (2), we add stock bid-ask spread and trading volume as control variables, and the results remain similar. The coefficient of the interaction term is $3.69(t=3.24)$.

Next, we repeat the analysis of the funding cost effect and firm size and credit rating in Section 4.2 using the European CMA sample and report the results in columns (3) and (4) in Panel A of Table 7. Consistent with Hypothesis 2, the coefficients of the terms $F \times S B \times S m a l l$ and $F \times S B \times$ Speculative are positive and statistically significant, suggesting that the funding effect is stronger for riskier or less liquid CDSs.

\subsection{Analyses based on CDS maturities}

Following our analysis of the funding cost effect using North American CDS contracts with different maturities in Section 4.3, we conduct an additional analysis using European CDS contracts with different maturities. We collect additional CDS data of 1-year, 3-year, 7-year and 10-year European CDS contracts from Datastream, and apply the same filters as those in Section 3.1. We first perform diff-in-diff regressions for each maturity, and the results are summarized in Panel B of Table 7. As shown in columns (1) to (4), the coefficient of $F \times S B$ increases monotonically with CDS maturities from $1 Y$ to $10 Y$. In column (5), we conduct diff-in-diff regressions for all maturities. The coefficient of the triple interaction $F \times S B \times$ Maturity is 0.84 and statistically significant $(t=2.9)$. Consistent with Hypothesis 3, our results suggest that the effect of upfront funding cost is stronger for CDS contracts with longer maturities.

\subsection{Analyses based on central clearing and Deutsche Bank exit}

We repeat our analysis of central clearing and the exit of Deutsche Bank using the European Markit sample. 
Central clearing of European CDSs started on December 14, 2009. We obtain the initial dates for central clearing for firms in our sample from the historical circulars issued by ICE Clear Europe from their official website (https://www.theice.com/clear-europe/circulars). To avoid the impact of the Deutsche Bank's exit in the single-name CDS market on the bid-ask spread, we use the sample period from April 1, 2010 to September 14, 2014. The regression results are reported in columns (1) and (2) in Panel C of Table 7. In column (1), the coefficient of $F^{\text {Markit }} \times$ Clear is $0.75(t=3.34)$ and statistically significant, suggesting that central clearing mitigates the effect of upfront funding cost on the bid-ask spread. We further use only the cleared sample which excludes firms that did not initiate central clearing in the period from April 1, 2010 to September 14, 2014. In column (2), the coefficient of $F^{\text {Markit }} \times$ Clear is $-0.57(t=2.0)$ and statistically significant, consistent with the result in column (1).

Following our analysis of the Deutsche Bank's exit in Section 4.5, we consider two different event dates: September 15, 2014 and November 17, 2014. The regression results are reported in columns (3) and (4) in Panel C of Table 7. Since central clearing of European CDS contracts started in December 2009, we also control for the effect of central clearing by including the interaction term $F^{\text {Markit }} \times$ Clear. The coefficient of $F^{\text {Markit }} \times D B$ is positive and statistically significant in both regressions, indicating that the effect of funding cost is stronger after the exit of Deutsche Bank.

\section{Robustness Checks and Further Discussions}

\subsection{European CDSs as a control group}

To account for potential confounding effects of unobserved shocks around the CDS Big Bang, we conduct a triple difference analysis using samples from both European and North American CDS markets. Since the CDS Big Bang applies only to North American CDS contracts, we can use European CDSs as a control group. Under the assumption that unobservable shocks have the same effects on the sensitivity of bid-ask spreads to $F$ across the two CDS markets, our triple 
difference test can account for the confounding effects of those unobservable shocks and identify the effect from the CDS Big bang.

For our main triple difference analysis, we choose the sample period as from January $25^{\text {th }}$ to June $19^{\text {th }}$ 2009. The end date is chosen because, on June 20, 2009, the CDS Small Bang took place for European CDS contracts. To avoid this confounding effect from the CDS Small Bang, we end our sample on the day before it was implemented. The starting date of this sample (January $25^{\text {th }}, 2009$ ) is chosen so that the pre- and post-Big-Bang samples have the same length (about two months). During the second half of this period (April $8^{\text {th }}$ to June $19^{\text {th }}$ ), the CDS Big Bang has been adopted for North American CDS contracts while the CDS Small Bang has not yet been implemented for European CDS contracts. This window of opportunity allows us to examine the effect from the CDS Big Bang, using European CDS contracts as a control.

We define a dummy variable $N A$, which is equal to 1 if the reference entity is a North American firm, otherwise 0 . We regress the CDS bid-ask spread on the triple interaction term $F \times B B \times N A$, and the results are reported in Table 8. In column (1), the coefficient for the triple interaction term is $1.66(t=2.61)$, suggesting that after the CDS Big Bang, bid-ask spreads become more sensitive to the upfront funding costs for North American CDS contracts, after controlling for the effect in the European sample. Moreover, the economic magnitude of this coefficient is comparable to the estimates in Table 2.

As in Section 4.1, we also conduct placebo tests to further test our hypothesis. Specifically, we pick two fictitious dates for the CDS Big Bang. Then, for each date, we repeat the above triple difference analysis using the sample from two months before the chosen date to two months after. In column (2), the chosen fictitious date is February 8, 2009. Hence, the entire sample period for this regression (from December 8, 2008 to April 7, 2009) is before the CDS Big Bang. Therefore, we expect the coefficient for the interaction term $F \times B B \times N A$ to be insignificant. Indeed, as shown in column (2), the estimate of this coefficient is $0.05(t=0.10)$. Similarly, for the placebo test in column (3), the chosen fictitious date is August 20, 2009, so that the entire sample for this regression is after both the CDS Big Bang and the CDS Small Bang. Hence, the triple interaction coefficient is also expected to be insignificant. Consistent with this 
conjecture, as shown in column (3), the estimate of this triple interaction coefficient is 0.61 $(t=0.52)$. These tests further support our interpretation that it is the upfront funding cost induced by the CDS Big Bang that has a cross-sectional effect on the CDS bid-ask spread.

\subsection{Alternative liquidity measures}

To enrich and broaden this study, we consider two alternative liquidity measures: CDS-bond basis and volatility of CDS spreads. A CDS-bond basis is the CDS spread minus the credit spread of the bond issued by the reference entity. Bai and Collin-Dufresne (2013) find that the CDS-bond basis is larger for bonds with higher funding costs. Our setting allows us to provide economic insights on the relation between the CDS-bond basis and the funding cost. The law of one price implies that in a frictionless market, the CDS-bond basis should be close to zero. A negative (positive) CDS-bond basis implies that the bond price is lower (higher) than what is implied by the CDS spread. A higher absolute value of the CDS-bond basis implies a stronger violation of the law of one price and leads to potential arbitrage opportunities. ${ }^{31}$

Despite the benefits of standardization, the CDS Big Bang induces upfront fees, which increase the funding cost of arbitrageurs. Therefore, the transition to the fixed coupons and upfront payments lowers the absolute value of the basis, but the decrease is smaller for contracts with large upfront payments. In other words, controlling for other effects, we expect that the absolute value of the CDS-bond basis is larger for contracts with larger upfront fees after the CDS Big Bang. Moreover, if the basis arbitrageur's strategy is such that she is the payer (rather than the receiver) of the upfront fee, the funding cost will further reduce her incentive to trade, leading to an even higher absolute value of the CDS-bond basis.

\footnotetext{
31 There was a persistent and negative CDS-bond basis during the global financial crisis. After the crisis, the size of the CDS-bond basis has gradually become smaller. As shown in Oehmke and Zawadowski (2015, 2017), there is a positive correlation between a more negative CDS-bond basis and the size of CDS positions taken by arbitrageurs. Therefore, it is reasonable to expect that CDS positions taken by basis arbitrageurs have declined after 2009. At the same time, it appears that market participants are still actively monitoring and exploiting basis arbitrage opportunities after 2009. For example, according to a report titled "US IG CDS-bond basis review" from Markit fixed-income research in July 2015, “[a]n analysis of the most liquid US investment grade 5 year CDSs which make up the 125 constituent of the Markit CDX NA IG and their corresponding reference bonds sees many such discrepancies which could be arbitraged away..." Therefore, we expect that the basis arbitrage activities have decreased after 2009 but not completely disappeared.
} 
Following previous studies (e.g., Elizalde, Doctor, and Saltuk (2009); Nashikkar, Subrahmanyam, and Mahanti (2011); Bai and Collin-Dufresne (2013); Choi, Shachar and Shin (2018)), we adopt the par equivalent CDS methodology to construct CDS-bond basis. In our North American CMA sample, the mean and median of CDS-bond basis is -22.47 and $-1.63 \mathrm{bps}$, respectively. For brevity, these statistics are not tabulated but are available upon request.

To test our predictions, we first regress the absolute value of the CDS-bond basis on the interaction term $F \times B B$. The results are reported in Table 9. In column (1), the coefficient for the interaction term is $37.79(t=4.10)$, suggesting that a higher upfront funding cost leads to a larger basis in absolute value. Second, we define a dummy variable Pay $y_{i t}$ which equals 1 if basis arbitrageurs pay the upfront fee, and 0 otherwise, depending on whether the basis is negative or positive. When the CDS-bond basis is negative, a basis arbitrageur's position is long in both the CDS and the underlying corporate bond, and we have:

$$
\text { Pay }_{i t}=\left\{\begin{array}{rr}
1, & \text { if } 100<S_{i t} \leq 300, \text { or } S_{i t}>500 \\
0, & \text { otherwise. }
\end{array}\right.
$$

Similarly, when the CDS-bond basis is positive, a basis arbitrageur's position is short in both the CDS and its underlying corporate bond, and so we have:

$$
\text { Pay }_{i t}=\left\{\begin{array}{rr}
1, & \text { if } 300<S_{i t} \leq 500, \text { or } S_{i t}<100 \\
0, & \text { otherwise. }
\end{array}\right.
$$

Our prediction is that the upfront funding effect is stronger if $P a y_{i t}=1$. Hence, we further regress $A B S$ (basis) on the triple interaction term $F \times B B \times P a y$. As shown in column (2), the coefficient for this triple interaction term is $21.71(t=1.94)$, consistent with our expectation. Note that the coefficient for $F \times B B$ is 26.92 ( $t=2.59$ ), comparable to the coefficient for the triple interaction term. This implies that when the basis arbitrageurs need to pay the upfront fee, the effect of upfront funding cost on $A B S$ (basis) is more than twice as strong as when arbitrageurs receive the upfront fee.

The second alternative liquidity measure that we consider is CDS volatility. The upfront funding cost is expected to increase the volatility of CDS spreads, since a less liquid market is less effective in absorbing temporary supply and demand shocks (see, e.g., Brunnermeier and 
Pedersen (2009, p. 2202)). Again, we take advantage of the setting of the CDS Big Bang. We have shown that, controlling for other effects, the bid-ask spread is larger for contracts with larger upfront fees. Therefore, we also expect that, controlling for other effects, the volatility of CDS spreads is larger for contracts with larger upfront fees.

For each CDS contract, on each day, we compute two volatility measures. CDS volatility (level) is the standard deviation of daily CDS levels during the previous two weeks. Its mean and median are 6.74 and 2.85 bps for the North American CMA sample. CDS volatility (change) is the standard deviation of daily CDS spread changes during the previous two weeks. Its mean and median are 4.88 and 2.36 bps for the North American CMA sample. For brevity, these statistics are not tabulated but are available upon request.

The regression results are reported in Table 9. In columns (3) and (4), where the CDS volatility is estimated based on spread levels and changes, respectively, the estimates of the coefficient for the interaction term $F \times B B$ are positive and highly significant, with t-statistics well over 4. Consistent with our expectation, the upfront funding cost leads to higher volatility.

\subsection{Alternative identification specification}

In the main analysis, our focus is the interaction term of $F \times B B$. However, $F$ is a product of $D I S$ and $L O I S$, and thus the interpretation of its coefficient needs more careful examination. In this subsection, we further examine the effect of its components separately. Specifically, we rerun the regressions in Table 2 using DIS (size of the upfront payment) and its interactions with the Big Bang dummy $B B$ and LOIS. We also include a quintic polynomial in CDS spreads to control for the general dependence of liquidity on the CDS spread, such as the CDS market being more liquid for certain credit spread levels due to higher trading activities for those contracts. As shown in column (1) in Table 10, the coefficient of DIS is statistically insignificant in the preBig-Bang sample suggesting that DIS does not have a differential effect on the CDS bid-ask spread before the CDS Big Bang. In column (2), the coefficient of DIS is $1.81(t=3.27)$ in the post-Big-Bang sample, indicating that DIS has a differential effect on the CDS bid-ask spread after the Big Bang. In column (3), the estimate of the interaction term $D I S \times B B$ is 1.91 and 
statistically significant, confirming that the bid-ask spread becomes sensitive to DIS only after the CDS Big Bang. In column (4), we further include a triple interaction terms $D I S \times B B \times L O I S$. The positive triple interaction term $D I S \times B B \times L O I S$ suggests that the CDS bid-ask spread becomes more sensitive to DIS when LOIS is higher after the CDS Big Bang. The coefficient of LOIS is positive and statistically significant, suggesting that the bid-ask spread is larger when LOIS is larger.

\subsection{Sample construction}

Our findings hold up to a battery of additional robustness tests. First, in Section 3.1, we choose the cutoff of CDS spreads to be $750 \mathrm{bps}$. We redo the main diff-in-diff regressions using the cutoff of 1000 bps. As shown in column (1) of Table 11, the coefficient of $F \times B B$ is positive and highly significant, consistent with the result in Panel A of Table 2. Instead of using the cutoff, we winsorize the sample at 99\%. Column (2) shows that the result is similar.

Second, the North American CMA sample used for the main diff-in-diff test in Table 2 includes some firms that had CDS trading before the CDS Big Bang but did not have CDS trading afterwards. To address this issue, we create a constant sample of 378 reference firms across the CDS Big Bang. As shown in column (3) of Table 11, the coefficient of $F \times B B$ is 2.36, which is very similar to that in Panel A of Table 2.

Third, in the previous analysis, we use the Amihud measure for bond liquidity because TRACE provides reliable and comprehensive bond transaction data, but does not provide bid and ask prices. Nevertheless, we collect bond bid and ask prices from Bloomberg and use the bid-ask spread as a liquidity control for bonds. As shown in column (4) of Table 11, our main results remain very similar when we include bond bid-ask spreads as a control variable.

\subsection{Overall effect}

As discussed earlier, the CDS Big Bang is expected to have at least two opposing effects on market liquidity. First, the standardization of CDS contracts is expected to enhance market liquidity. Second, the upfront funding cost arising from the fixed coupons is expected to reduce market liquidity of firms with different levels of CDS spreads. Thus, the overall effect on market 
liquidity consists of two components: the effect arising from the benefits of standardization and the upfront funding effect. One can estimate the relative strength of these two components by removing the time-fixed effects in our main regression in Table 2 . The upfront funding effect is captured by the coefficient of $F \times B B$, and other effects are captured by the coefficient of $B B$. To minimize potential confounding effects, we focus on short time windows around the CDS Big Bang and the regression results are reported in Panel A of Table 12.

In columns (1), (3), (5), and (7), the regressions are based on the sample from 3-6 months before the CDS Big Bang to 3-6 months after. The estimate of the coefficient of $B B$ decreases monotonically from -0.62 (3 months) to -2.14 (6 months). This is consistent with the notion that the standardization from the CDS Big Bang improves market liquidity. Moreover, as in our earlier regressions, the coefficient of $F \times B B$ is significantly positive, suggesting that the upfront funding cost decreases market liquidity.

The overall market liquidity effect from the CDS Big Bang is a tradeoff between the two opposing effects, and it can be estimated by removing the interaction term. The regressions in columns (2), (4), (6), and (8) are based on the sample from 3-6 months before to 3-6 months after the CDS Big Bang. The coefficient of $B B$ decreases monotonically from 0.34 to -0.72 . This result suggests that, as CDS traders become more familiar with the new rules, the benefit from standardization increases and the overall effect becomes liquidity enhancing.

Next, we turn to our European data set to estimate the overall effect of the CDS Small Bang. Since the implementation date of the Small Bang is June 20, 2009, which is about two and a half months later than the CDS Big Bang, we expect that the beneficial effect of standardization for the CDS Small Bang is incorporated into CDS trading more quickly. Furthermore, the CDS Small Bang allows four fixed coupons and thus the funding cost effect is expected to be smaller. The results are reported in Panel B of Table 12. In columns (2), (4), (6), and (8), the coefficient of $S B$ is all negative and statistically significant, indicating that the overall effect of the CDS Small Bang is liquidity enhancing. 


\section{Conclusion}

The CDS Big Bang is an important step towards standardizing the CDS market. We exploit this historical event to provide economic insights on the effect of funding liquidity. This funding shock, combined with several other shocks that took place soon afterwards (the CDS Small Bang, central clearing, and Deutsche Bank's exit from the CDS market) offers a rich setup to not only quantify the negative market liquidity effect from funding shocks, but also examine the economic mechanism behind this effect.

Our main analyses, based on the CDS Big Bang applied to North American CDS contracts on April 8, 2009, show that the upfront funding cost has a cross-sectional effect on the CDS bid-ask spread. Moreover, this funding effect is stronger for CDSs with smaller or riskier reference entities and contracts with longer maturities. We further conduct in-depth analyses using the implementation of central clearing and the event of Deutsche Bank exiting the CDS market. Our evidence suggests that central clearing alleviates the funding effect through more efficient netting. Consistent with the theoretical prediction that the funding cost has a large effect when traders are close to their constraints, we find that the funding effect becomes stronger after the exit of Deutsche Bank, a major market maker in the CDS market. Finally, we provide additional supporting evidence on the effect of funding liquidity and the overall effect of the trading convention changes using the CDS Small Bang applied to European CDS contracts. 


\section{References}

Acharya, Viral V., Stephen M. Schaefer, and Yili Zhang, 2015, Liquidity risk and correlation risk: A clinical study of the general motors and ford downgrade of 2005, Quarterly Journal of Finance 5:1-51.

Adrian, Tobias, Erkko Etula, and Tyler Muir, 2014, Financial intermediaries and the crosssection of asset returns, Journal of Finance 69:2557-2596.

Amihud, Yakov, 2002, Illiquidity and stock returns: Cross-section and time-series effects, Journal of Financial Markets 5:31-56.

Andersen, Leif, Darrell Duffie, and Yang Song, 2017, Funding value adjustments, Journal of Finance (forthcoming).

Aragon, George O., and Philip E. Strahan, 2012, Hedge funds as liquidity providers: Evidence from the Lehman bankruptcy, Journal of Financial Economics 103:570-587.

Augustin, Patrick, Marti G. Subrahmanyam, Dragon Y. Tang, and Sarah Q. Wang, 2016, Credit default swaps: Past, present, and future, Annual Review of Financial Economics 8:175196.

Bai, Jennie, and Pierre Collin-Dufresne, 2013, The CDS-bond basis, Working paper, Georgetown University.

Basak, Suleyman, and Benjamin Croitoru, 2000, Equilibrium mispricing in a capital market with portfolio constraints, Review of Financial Studies 13:715-748.

Bongaerts, Dion, Frank De Jong, and Joost Driessen, 2011, Derivative pricing with liquidity risk: Theory and evidence from the credit default swap market, Journal of Finance 66:203240.

Brunnermeier, Markus K., and Lasse Heje Pedersen, 2009, Market liquidity and funding liquidity, Review of Financial Studies 22:2201-2238.

Brunnermeier, Markus K., and Yuliy Sannikov, 2014, A macroeconomic model with a financial sector, American Economic Review 104:379-421.

Chen, Kathryn, Michael Fleming, John Jackson, Ada Li, and Asani Sarkar, 2011, An analysis of CDS transactions: Implications for public reporting, Staff report 517. Federal Reserve Bank of New York, NY.

Chen, Ren-Raw, Xiaolin Cheng, and Liuren Wu, 2013, Dynamic interactions between interestrate and credit risk: Theory and evidence on the credit default swap term structure, Review of Finance 17:403-441.

Choi, Jaewon, Or Shachar and Sean Seunghun Shin, 2018, Dealer liquidity provision and the breakdown of the law of one price: Evidence from the CDS-bond basis, Management Science (Forthcoming).

Chordia, Tarun, Asani Sarkar, and Avanidhar Subrahmanyam, 2005, An empirical analysis of stock and bond market liquidity, Review of Financial Studies 18:85-129.

Comerton-Forde, Carole, Terrence Hendershott, Charles M. Jones, Pamela C. Moulton, and Mark S. Seasholes, 2010, Time variation in liquidity: The role of market-maker inventories and revenues, Journal of Finance 65:295-331. 
Coughenour, Jay F., and Mohsen M. Saad, 2004, Common market makers and commonality in liquidity, Journal of Financial Economics 73:37-69.

Danis, Andras, 2017, Do empty creditors matter? Evidence from distressed exchange offers, Management Science 63:1285-1301.

Dick-Nielsen, Jens, Peter Feldhütter, and David Lando, 2012, Corporate bond liquidity before and after the onset of the subprime crisis, Journal of Financial Economics 103:471-492.

Duffie, Darrel, Martin Scheicher, and Guillaume Vuillemey, 2015, Central clearing and collateral demand, Journal of Financial Economics 116:237-256.

Duffie, Darrell, Ada Li, and Theo Lubke, 2010, Policy perspectives on OTC derivatives market infrastructure, Federal Reserve Bank of New York Staff Reports.

Duffie, Darrell, and Haoxiang Zhu, 2011, Does a central clearing counterparty reduce counterparty risk?, Review of Asset Pricing Studies 1:74-95.

Elizalde, Abel, Saul Doctor, and Yasemin Saltuk, 2009, Bond-CDS Basis Handbook, J. P. Morgan Credit Derivatives Research.

Gârleanu, Nicolae, and Lasse Heje Pedersen, 2011, Margin-based asset pricing and deviations from the law of one price, Review of Financial Studies 24:1980-2022.

Gromb, Denis, and Dimitri Vayanos, 2002, Equilibrium and welfare in markets with financially constrained arbitrageurs, Journal of Financial Economics 66:361-407.

Grossman, Sanford J, and Merton H Miller, 1988, Liquidity and market structure, Journal of Finance 43:617-633.

Gunduz, Yalin, Steven Ongena, Gunseli Tumer-Alkan, and Yuejuan Yu, 2017, CDS and credit: Testing the Small Bang theory of the financial universe with micro data, working paper.

Haas, Marlene, and Julia Reynolds, 2017, Illiquidity contagion and information spillover from CDS to equity markets, Working paper.

Hameed, Allaudeen, Wenjin Kang, and S. Viswanathan, 2010, Stock market declines and liquidity, Journal of Finance 65:257-293.

He, Zhiguo, Bryan Kelly, and Asaf Manela, 2017, Intermediary asset pricing: New evidence from many asset classes, Journal of Financial Economics 126:1-35.

He, Zhiguo, and Arvind Krishnamurthy, 2013, Intermediary asset pricing, American Economic Review 103:732-770.

Karolyi, G. Andrew, Kuan Hui Lee, and Mathijs A. Van Dijk, 2012, Understanding commonality in liquidity around the world, Journal of Financial Economics 105:82-112.

Kyle, Albert S, and Wei Xiong, 2001, Contagion as a wealth effect, Journal of Finance 56:14011440.

Longstaff, Francis A., Sanjay Mithal, and Eric Neis, 2005, Corporate yield spreads: Default risk or liquidity? New evidence from the credit default swap market, Journal of Finance 60:2213-2253.

Loon, Yee Cheng, and Zhaodong Ken Zhong, 2014, The impact of central clearing on counterparty risk, liquidity, and trading: Evidence from the credit default swap market, Journal of Financial Economics 112:91-115. 
Mitchell, Mark, Lasse Heje Pedersen, and Todd Pulvino, 2007, Slow moving capital, American Economic Review (Papers \& Proceedings) 97:215-220.

Mitchell, Mark, and Todd Pulvino, 2012, Arbitrage crashes and the speed of capital, Journal of Financial Economics 104:469-490.

Nashikkar, Amrut, Marti G Subrahmanyam, and Sriketan Mahanti, 2011, Liquidity and arbitrage in the market for credit risk, Journal of Financial and Quantitative Analysis 46:627-656.

Oehmke, Martin, and Adam Zawadowski, 2015, Synthetic or real? The equilibrium effects of credit default swaps on bond markets, Review of Financial Studies 28:3303-3337.

Oehmke, Martin, and Adam Zawadowski, 2017, The anatomy of the CDS market, Review of Financial Studies 30:80-119.

Qiu, Jiaping, and Fan Yu, 2012, Endogenous liquidity in credit derivatives, Journal of Financial Economics 103:611-631.

Shachar, Or, 2012, Exposing the exposed: Intermediation capacity in the credit default swap market, Working paper.

Shen, Ji, Hongjun Yan, and Jinfan Zhang, 2014, Collateral-motivated financial innovation, Review of Financial Studies 27:2961-2997.

Shleifer, Andrei, and Robert Vishny, 1997, The limits of arbitrage, Journal of Finance 52:35-55.

Stulz, Rene M, 2010, Credit default swaps and the credit crisis, Journal of Economic Perspectives 24:73-92.

Tang, Dragon Yongjun, and Hong Yan, 2007, Liquidity and credit default swap spreads, Working paper, University of Hong Kong.

Xiong, Wei, 2001, Convergence trading with wealth effects: An amplification mechanism in financial markets, Journal of Financial Economics 62:247-292. 


\section{Table 1. Summary statistics}

Panel A provides summary statistics of the North American CMA sample on 634 North American companies from January 1, 2004 to September 30, 2010. Panel B provides summary statistics of the North American Markit sample on 765 North American companies from April 1, 2010 to October 19, 2016. Panel C provides summary statistics of the European CMA sample on 423 European companies from January 1, 2004 to September 30, 2010. Panel D provides summary statistics of the European Markit sample on 547 European companies from April 1, 2010 to October 19, 2016. Bid-ask spread is the difference between bid and ask quotes on CDS spreads, denominated in bps. $S$ is the midpoint of bid and ask quotes of CDS spreads, in bps. DIS is defined in Equation (1). LOIS is the 3-month Libor rate minus the 3-month OIS rate, denoted in percentage, and is from Bloomberg. VIX is the daily close value of the CBOE volatility index expressed in percentage, and is from Datastream. We also use VIX' to denote the orthogonalized VIX, the residual from regressing VIX on LOIS. Leverage is the ratio of total liability to total asset. Stock volatility is the two-week rolling standard deviation of stock returns. Log(stock volume) is the logarithm of the daily stock trading volume, in number of shares, of the reference entity. Stock bidask spread is the ask price minus the bid price divided by the midpoint of the bid and ask prices of the stock price of the reference entity, denoted in bps. Both Stock volume and Stock bid-ask spread are from CRSP. Log(bond volume) is the logarithm of the daily trading volume (denominated in dollars in face value) of the reference entity's bonds, according to TRACE. Log(bond Amihud) is the logarithm of the Amihud (2002) measure calculated for the reference entity's bonds. Fee is the size of the upfront payment provided by Markit, expressed in percentage of the notional value. LOIS Euro is the spread between 3 month Euro Libor rate and 3 month Euro OIS rate, denoted in percentage. VSTOXX is the daily close value of the EURO STOXX 50 volatility index, expressed in percentage. 
Panel A: North American CMA sample (January 1, 2004 to September 30, 2010)

\begin{tabular}{lrrrrrr}
\hline Variable & $\mathrm{N}$ & Mean & Std Dev & 1st Pctl & 50th Pctl & 99th Pctl \\
\hline Bid-ask spread & 633,977 & 9.61 & 8.28 & 2.00 & 5.30 & 40.00 \\
S & 633,977 & 136.69 & 152.80 & 9.00 & 71.20 & 681.22 \\
DIS & 633,977 & 0.67 & 0.45 & 0.02 & 0.62 & 1.98 \\
LOIS & 633,975 & 0.32 & 0.45 & 0.05 & 0.11 & 2.53 \\
VIX & 633,977 & 20.44 & 10.54 & 10.23 & 17.18 & 63.92 \\
Leverage & 579,937 & 0.67 & 0.18 & 0.32 & 0.66 & 1.12 \\
Stock volatility & 543,649 & 0.02 & 0.02 & 0.00 & 0.02 & 0.08 \\
Log(stock volume) & 541,845 & 14.70 & 1.40 & 10.64 & 14.70 & 17.82 \\
Stock bid-ask spread & 542,578 & 9.97 & 22.55 & 0.00 & 5.43 & 79.09 \\
Log(bond volume) & 393,615 & 15.01 & 2.14 & 9.62 & 15.43 & 18.84 \\
Log(bond Amihud) & 393,615 & -15.52 & 2.22 & -22.43 & -14.92 & -12.00 \\
\hline
\end{tabular}

Panel B: North American Markit sample (April 1, 2010 to October 19, 2016)

\begin{tabular}{lrrrrrr}
\hline Variable & $\mathrm{N}$ & Mean & Std Dev & 1st Pctl & 50th Pctl & 99th Pctl \\
\hline Bid-ask spread & 659,618 & 12.39 & 9.36 & 4.00 & 10.00 & 47.17 \\
S & 659,618 & 154.52 & 145.48 & 15.33 & 101.99 & 675.73 \\
Fee & 659,618 & 4.07 & 4.15 & 0.06 & 2.76 & 19.08 \\
LOIS & 659,618 & 0.20 & 0.09 & 0.09 & 0.16 & 0.49 \\
VIX & 657,810 & 18.09 & 6.00 & 11.36 & 16.37 & 39.76 \\
Leverage & 422,882 & 0.68 & 0.18 & 0.36 & 0.65 & 1.29 \\
Stock volatility & 425,902 & 0.02 & 0.01 & 0.00 & 0.01 & 0.05 \\
Log(stock volume) & 425,382 & 14.71 & 1.41 & 9.62 & 14.78 & 17.60 \\
Stock bid-ask spread & 425,904 & 4.27 & 8.51 & 0.54 & 2.68 & 25.27 \\
Log(bond volume) & 416,762 & 14.90 & 2.16 & 9.39 & 15.29 & 18.83 \\
Log(bond Amihud) & 407,582 & -15.61 & 1.71 & -21.39 & -15.28 & -12.52 \\
\hline
\end{tabular}


Panel C: European CMA sample (January 1, 2004 to September 30, 2010)

\begin{tabular}{lrrrrrr}
\hline Variable & $\mathrm{N}$ & Mean & Std Dev & 1st Pctl & 50th Pctl & 99th Pctl \\
\hline Bid-ask spread & 421,667 & 8.64 & 9.19 & 1.75 & 5.00 & 47.00 \\
$S$ & 421,667 & 113.71 & 136.96 & 6.50 & 59.50 & 640.00 \\
DIS & 421,667 & 0.37 & 0.47 & 0.00 & 0.19 & 1.95 \\
VSTOXX & 420,728 & 23.33 & 10.32 & 12.25 & 20.63 & 63.66 \\
LOIS Euro & 421,667 & 0.29 & 0.36 & 0.03 & 0.07 & 1.69 \\
Stock bid-ask spread & 260,368 & 61.77 & 85.82 & 1.29 & 21.30 & 357.14 \\
Log(stock volume) & 259,317 & 5.43 & 3.47 & 0.00 & 6.07 & 11.70 \\
\hline
\end{tabular}

Panel D: European Markit sample (April 1, 2010 to October 19, 2016)

\begin{tabular}{lrrrrrr}
\hline Variable & $\mathrm{N}$ & Mean & Std Dev & 1st Pctl & 50th Pctl & 99th Pctl \\
\hline Bid-ask spread & 480,117 & 12.57 & 9.80 & 3.50 & 10.00 & 50.00 \\
S & 480,117 & 156.66 & 137.89 & 25.75 & 104.65 & 667.75 \\
Fee & 480,117 & 4.42 & 5.14 & 0.05 & 2.35 & 21.12 \\
VSTOXX & 477,565 & 23.64 & 6.66 & 14.15 & 22.15 & 46.68 \\
LOIS Euro & 480,117 & 0.17 & 0.19 & 0.01 & 0.10 & 0.87 \\
Stock bid-ask spread & 328,415 & 68.46 & 85.32 & 1.07 & 34.68 & 363.64 \\
Log(stock volume) & 333,468 & 4.36 & 3.37 & 0.00 & 3.70 & 11.68 \\
\hline
\end{tabular}




\section{Table 2. Effect of upfront funding cost around the CDS Big Bang}

Panel A reports the effect of upfront funding cost $F$ on Bid-ask spread based on the North American CMA sample (January 1, 2004 to September 30, 2010). The dependent variable is Bid-ask spread. $F$ is a proxy for the upfront funding cost based on DIS as defined in Equation (2). $F^{I S D A}$ is the upfront funding cost calculated using the ISDA CDS standard model as defined in Equation (3). $B B$ is a dummy variable that is 1 if the date is later than April 8, 2009, and 0 otherwise. All other variables are defined in Table 1. Interaction terms between $B B$ and control variables are not reported in the table. Panel B reports results from the placebo tests. Columns (1)/(4) and (2)/(5) are based on regressions with fictitious dates for the CDS Big Bang, October 8, 2008 and October 8, 2009, respectively, while columns (3)/(6) is based on the actual event date, April 8, 2009. Firm-fixed effects and monthly time-fixed effects are included in all regressions. Numbers in parentheses are $t$-statistics based on standard errors that are clustered by firm and are corrected for heteroscedasticity. $* * *$, and $* * *$ denote statistical significance at the $10 \%, 5 \%$, and $1 \%$ level, respectively. 
Panel A: Upfront funding cost and market liquidity

\begin{tabular}{|c|c|c|c|c|c|c|}
\hline & $\begin{array}{c}(1) \\
\text { Pre-BB }\end{array}$ & $\begin{array}{c}(2) \\
\text { Post-BB }\end{array}$ & $\begin{array}{c}\text { (3) } \\
\text { Overall }\end{array}$ & $\begin{array}{c}(4) \\
\text { Pre-BB }\end{array}$ & $\begin{array}{c}(5) \\
\text { Post-BB }\end{array}$ & $\begin{array}{c}(6) \\
\text { Overall }\end{array}$ \\
\hline$F$ & $\begin{array}{c}0.59 * * * \\
(5.46)\end{array}$ & $\begin{array}{c}2.89 * * * \\
(7.92)\end{array}$ & $\begin{array}{c}0.62 * * * \\
(5.90)\end{array}$ & & & \\
\hline$F \times B B$ & & & $\begin{array}{c}2.36^{* * * *} \\
(6.08)\end{array}$ & & & \\
\hline$F^{I S D A}$ & & & & $\begin{array}{c}0.15^{* * *} \\
(5.63)\end{array}$ & $\begin{array}{c}0.66 * * * * \\
(7.49)\end{array}$ & $\begin{array}{c}0.16^{* * * *} \\
(6.07)\end{array}$ \\
\hline$F^{I S D A} \times B B$ & & & & & & $\begin{array}{c}0.53 * * * \\
(5.66)\end{array}$ \\
\hline$B B$ & & & $\begin{array}{c}-2.15 \\
(-1.58)\end{array}$ & & & $\begin{array}{c}-2.03 \\
(-1.48)\end{array}$ \\
\hline$S$ & $\begin{array}{c}0.03 * * * \\
(29.16)\end{array}$ & $\begin{array}{l}0.03 * * * \\
(20.29)\end{array}$ & $\begin{array}{c}0.03 * * * \\
(29.90)\end{array}$ & $\begin{array}{c}0.03 * * * \\
(29.59)\end{array}$ & $\begin{array}{l}0.03 * * * \\
(20.81)\end{array}$ & $\begin{array}{l}0.03 * * * \\
(30.47)\end{array}$ \\
\hline Leverage & $\begin{array}{c}-2.71 * * \\
(-2.42)\end{array}$ & $\begin{array}{c}0.19 \\
(0.06)\end{array}$ & $\begin{array}{c}-1.96 * * \\
(-2.13)\end{array}$ & $\begin{array}{c}-2.71 * * \\
(-2.42)\end{array}$ & $\begin{array}{c}0.18 \\
(0.06)\end{array}$ & $\begin{array}{c}-2.20 * * \\
(-2.29)\end{array}$ \\
\hline Stock volatility & $\begin{array}{c}15.82 * * * \\
(4.41)\end{array}$ & $\begin{array}{c}23.54 * * * \\
(5.21)\end{array}$ & $\begin{array}{c}17.30^{* * * *} \\
(4.81)\end{array}$ & $\begin{array}{c}15.90^{* * * *} \\
(4.42)\end{array}$ & $\begin{array}{c}24.18 * * * \\
(5.29)\end{array}$ & $\begin{array}{c}19.34 * * * \\
(4.97)\end{array}$ \\
\hline Log(stock volume) & $\begin{array}{c}0.08 \\
(1.44)\end{array}$ & $\begin{array}{c}0.04 \\
(0.61)\end{array}$ & $\begin{array}{c}0.02 \\
(0.35)\end{array}$ & $\begin{array}{c}0.08 \\
(1.42)\end{array}$ & $\begin{array}{c}0.04 \\
(0.53)\end{array}$ & $\begin{array}{c}0.01 \\
(0.23)\end{array}$ \\
\hline Log(bond volume) & $\begin{array}{l}-0.02 * \\
(-1.91)\end{array}$ & $\begin{array}{c}-0.03 * * \\
(-2.14)\end{array}$ & $\begin{array}{l}-0.02^{*} \\
(-1.76)\end{array}$ & $\begin{array}{l}-0.02 * \\
(-1.91)\end{array}$ & $\begin{array}{c}-0.03 * * \\
(-2.21)\end{array}$ & $\begin{array}{l}-0.02 * \\
(-1.72)\end{array}$ \\
\hline $\log ($ bond Amihud $)$ & $\begin{array}{c}0.01 \\
(0.95)\end{array}$ & $\begin{array}{c}-0.04 * * * \\
(-2.70)\end{array}$ & $\begin{array}{c}0.01 \\
(0.93)\end{array}$ & $\begin{array}{c}0.01 \\
(0.92)\end{array}$ & $\begin{array}{c}-0.04 * * * \\
(-2.78)\end{array}$ & $\begin{array}{c}0.01 \\
(0.90)\end{array}$ \\
\hline Stock bid-ask spread & $\begin{array}{l}0.00^{*} \\
(1.74)\end{array}$ & $\begin{array}{c}0.00 \\
(0.28)\end{array}$ & $\begin{array}{c}0.00 \\
(1.40)\end{array}$ & $\begin{array}{l}0.00^{*} \\
(1.73)\end{array}$ & $\begin{array}{c}0.00 \\
(0.32)\end{array}$ & $\begin{array}{c}0.00 \\
(1.47)\end{array}$ \\
\hline LOIS & $\begin{array}{c}0.47 * * * \\
(3.17)\end{array}$ & $\begin{array}{c}0.55 \\
(1.42)\end{array}$ & $\begin{array}{c}0.45^{* * *} \\
(3.10)\end{array}$ & $\begin{array}{c}0.45^{* * *} * \\
(2.98)\end{array}$ & $\begin{array}{c}0.57 \\
(1.45)\end{array}$ & $\begin{array}{c}0.41 * * * \\
(2.86)\end{array}$ \\
\hline$V I X^{\prime}$ & $\begin{array}{c}0.01 \\
(1.49)\end{array}$ & $\begin{array}{c}-0.00 \\
(-0.73)\end{array}$ & $\begin{array}{c}0.01 \\
(1.60)\end{array}$ & $\begin{array}{c}0.01 \\
(1.47)\end{array}$ & $\begin{array}{c}-0.00 \\
(-0.83)\end{array}$ & $\begin{array}{c}0.01 \\
(1.41)\end{array}$ \\
\hline Observations & 252,449 & 102,221 & 354,670 & 252,449 & 102,221 & 354,635 \\
\hline R-squared & 0.675 & 0.572 & 0.684 & 0.675 & 0.571 & 0.684 \\
\hline Number of firms & 450 & 387 & 459 & 450 & 387 & 459 \\
\hline
\end{tabular}


Panel B: Placebo tests

\begin{tabular}{|c|c|c|c|c|c|c|}
\hline $\begin{array}{c}\text { Event date } \\
\text { Sample period }\end{array}$ & $\begin{array}{c}(1) \\
\text { Placebo test } 1 \\
10 / 08 / 2008 \\
4 / 8 / 2008- \\
4 / 7 / 2009 \\
\end{array}$ & $\begin{array}{c}(2) \\
\text { Placebo test } 2 \\
10 / 08 / 2009 \\
4 / 8 / 2009- \\
4 / 7 / 2010 \\
\end{array}$ & $\begin{array}{c}(3) \\
\text { Baseline test } \\
04 / 08 / 2009 \\
10 / 8 / 2008- \\
10 / 7 / 2009 \\
\end{array}$ & $\begin{array}{c}(4) \\
\text { Placebo test } 1 \\
10 / 08 / 2008 \\
4 / 8 / 2008- \\
4 / 7 / 2009 \\
\end{array}$ & $\begin{array}{c}(5) \\
\text { Placebo test } 2 \\
10 / 08 / 2009 \\
4 / 8 / 2009- \\
4 / 7 / 2010 \\
\end{array}$ & $\begin{array}{c}(6) \\
\text { Baseline test } \\
04 / 08 / 2009 \\
10 / 8 / 2008- \\
10 / 7 / 2009 \\
\end{array}$ \\
\hline$F$ & $\begin{array}{c}0.70^{* * * *} \\
(3.66)\end{array}$ & $\begin{array}{c}2.56 * * * \\
(7.31)\end{array}$ & $\begin{array}{c}0.26^{* * * *} \\
(2.96)\end{array}$ & & & \\
\hline$F \times B B$ & $\begin{array}{l}-0.31 \\
(-1.49)\end{array}$ & $\begin{array}{c}0.32 \\
(0.16)\end{array}$ & $\begin{array}{c}1.86^{* * * *} \\
(6.95)\end{array}$ & & & \\
\hline$F^{I S D A}$ & & & & $\begin{array}{c}0.18 * * * \\
(3.77)\end{array}$ & $\begin{array}{c}0.58 * * * \\
(6.87)\end{array}$ & $\begin{array}{c}0.07 \text { **** } \\
(3.08)\end{array}$ \\
\hline$F^{I S D A} \times B B$ & & & & $\begin{array}{c}-0.08 \\
(-1.54)\end{array}$ & $\begin{array}{c}0.22 \\
(0.48)\end{array}$ & $\begin{array}{c}0.43^{* * * *} \\
(6.71)\end{array}$ \\
\hline$B B$ & $\begin{array}{c}1.30 * * * \\
(2.99)\end{array}$ & $\begin{array}{c}-0.72 * * * \\
(-4.23)\end{array}$ & $\begin{array}{c}-0.65 * * * \\
(-3.09)\end{array}$ & $\begin{array}{c}1.35^{* * * *} \\
(2.98)\end{array}$ & $\begin{array}{c}-0.77 * * * \\
(-4.35)\end{array}$ & $\begin{array}{c}-0.64 * * * \\
(-2.98)\end{array}$ \\
\hline$S$ & $\begin{array}{c}0.03 * * * \\
(24.23)\end{array}$ & $\begin{array}{l}0.03 * * * \\
(25.53)\end{array}$ & $\begin{array}{l}0.03^{* * * *} \\
(21.65)\end{array}$ & $\begin{array}{c}0.03^{* * * *} \\
(24.63)\end{array}$ & $\begin{array}{c}0.03 * * * \\
(26.12)\end{array}$ & $\begin{array}{l}0.03^{* * * *} \\
(22.09)\end{array}$ \\
\hline Leverage & $\begin{array}{c}-6.59^{* * *} \\
(-3.19)\end{array}$ & $\begin{array}{c}0.56 \\
(0.16)\end{array}$ & $\begin{array}{c}-0.30 \\
(-0.12)\end{array}$ & $\begin{array}{c}-6.50 * * * \\
(-3.15)\end{array}$ & $\begin{array}{c}0.57 \\
(0.16)\end{array}$ & $\begin{array}{c}-0.28 \\
(-0.12)\end{array}$ \\
\hline Stock volatility & $\begin{array}{l}7.12 * * \\
(2.22)\end{array}$ & $\begin{array}{c}21.22 * * * \\
(4.46)\end{array}$ & $\begin{array}{c}1.34 \\
(0.46)\end{array}$ & $\begin{array}{l}7.16^{* *} \\
(2.22)\end{array}$ & $\begin{array}{c}21.77 * * * \\
(4.52)\end{array}$ & $\begin{array}{c}1.32 \\
(0.45)\end{array}$ \\
\hline Log(stock volume) & $\begin{array}{c}0.05 \\
(0.61)\end{array}$ & $\begin{array}{c}0.11 \\
(1.52)\end{array}$ & $\begin{array}{c}0.26 * * * \\
(2.80)\end{array}$ & $\begin{array}{l}0.05 \\
(0.59)\end{array}$ & $\begin{array}{c}0.11 \\
(1.44)\end{array}$ & $\begin{array}{c}0.26 * * * \\
(2.82)\end{array}$ \\
\hline Log(bond volume) & $\begin{array}{l}-0.01 \\
(-0.88)\end{array}$ & $\begin{array}{l}-0.02 * \\
(-1.70)\end{array}$ & $\begin{array}{l}-0.03 \\
(-1.57)\end{array}$ & $\begin{array}{l}-0.01 \\
(-0.89)\end{array}$ & $\begin{array}{l}-0.02 * \\
(-1.78)\end{array}$ & $\begin{array}{l}-0.03 \\
(-1.55)\end{array}$ \\
\hline Log(bond Amihud) & $\begin{array}{c}0.02 \\
(1.18)\end{array}$ & $\begin{array}{l}-0.02^{*} \\
(-1.66)\end{array}$ & $\begin{array}{l}-0.01 \\
(-0.72)\end{array}$ & $\begin{array}{c}0.02 \\
(1.14)\end{array}$ & $\begin{array}{l}-0.02 * \\
(-1.75)\end{array}$ & $\begin{array}{l}-0.01 \\
(-0.74)\end{array}$ \\
\hline Stock bid-ask spread & $\begin{array}{c}0.00 * * * \\
(3.41)\end{array}$ & $\begin{array}{c}0.00 \\
(0.84)\end{array}$ & $\begin{array}{c}-0.00 \\
(-0.34)\end{array}$ & $\begin{array}{c}0.00 * * * \\
(3.41)\end{array}$ & $\begin{array}{c}0.00 \\
(0.88)\end{array}$ & $\begin{array}{c}-0.00 \\
(-0.34)\end{array}$ \\
\hline LOIS & $\begin{array}{c}0.53 * * * \\
(3.33)\end{array}$ & $\begin{array}{c}-0.42 \\
(-0.89)\end{array}$ & $\begin{array}{c}-0.20 \\
(-0.96)\end{array}$ & $\begin{array}{c}0.50 * * * \\
(3.12)\end{array}$ & $\begin{array}{c}-0.42 \\
(-0.88)\end{array}$ & $\begin{array}{c}-0.21 \\
(-1.01)\end{array}$ \\
\hline$V I X^{\prime}$ & $\begin{array}{c}-0.02 * * * \\
(-4.32)\end{array}$ & $\begin{array}{c}-0.06 * * * \\
(-8.09)\end{array}$ & $\begin{array}{c}-0.04 * * * \\
(-6.90)\end{array}$ & $\begin{array}{c}-0.02 * * * \\
(-4.37)\end{array}$ & $\begin{array}{c}-0.06 * * * \\
(-8.20)\end{array}$ & $\begin{array}{c}-0.04 * * * \\
(-6.93)\end{array}$ \\
\hline Observations & 54,284 & 66,767 & 57,727 & 54,284 & 66,767 & 57,727 \\
\hline R-squared & 0.695 & 0.604 & 0.514 & 0.696 & 0.603 & 0.513 \\
\hline Number of firms & 376 & 375 & 369 & 376 & 375 & 369 \\
\hline
\end{tabular}




\section{Table 3. Effect of upfront funding cost for firms with different sizes and credit ratings}

This table reports the effect of upfront funding cost $F$ on Bid-ask spread for firms with different sizes and credit ratings based on the North American CMA sample (January 1, 2004 to September 30, 2010). The dependent variable is Bid-ask spread. BB is a dummy variable that is 1 if the date is later than April 8, 2009, and 0 otherwise. Small is a dummy variable that is 1 if the reference entity's asset is below the median, and 0 otherwise. Speculative is a dummy variable that is 1 if the reference entity's credit rating is below BBB, and 0 otherwise. All other variables are defined in Table 1. The interaction terms between $B B$ and control variables are not reported in the table. Firm-fixed effects and monthly time-fixed effects are included in all regressions. Numbers in parentheses are $t$-statistics based on standard errors that are clustered by firm and are corrected for heteroscedasticity. *, **, and *** denote statistical significance at the $10 \%, 5 \%$, and $1 \%$ level, respectively.

Firm size

\begin{tabular}{|c|c|c|}
\hline$F$ & $\begin{array}{c}0.72 * * * \\
(4.87)\end{array}$ & $\begin{array}{c}0.77 * * * \\
(6.59)\end{array}$ \\
\hline$F \times B B$ & $\begin{array}{c}1.64 * * * \\
(3.44)\end{array}$ & $\begin{array}{c}1.91 * * * \\
(4.58)\end{array}$ \\
\hline$B B$ & $\begin{array}{c}-1.30 \\
(-0.90)\end{array}$ & $\begin{array}{c}-1.98 \\
(-1.43)\end{array}$ \\
\hline$F \times B B \times$ Small & $\begin{array}{c}1.34 * * * \\
(2.63)\end{array}$ & \\
\hline$F \times B B \times$ Speculative & & $\begin{array}{l}1.33 * * \\
(2.02)\end{array}$ \\
\hline$S$ & $\begin{array}{c}0.03 * * * \\
(30.18)\end{array}$ & $\begin{array}{c}0.03 * * * \\
(29.85)\end{array}$ \\
\hline Leverage & $\begin{array}{c}-1.92 * * \\
(-2.08)\end{array}$ & $\begin{array}{c}-1.98 * * \\
(-2.13)\end{array}$ \\
\hline Stock volatility & $\begin{array}{c}16.61 * * * \\
(4.58)\end{array}$ & $\begin{array}{c}16.76 * * * \\
(4.65)\end{array}$ \\
\hline Log(stock volume) & $\begin{array}{c}0.03 \\
(0.50)\end{array}$ & $\begin{array}{c}0.01 \\
(0.26)\end{array}$ \\
\hline Log(bond volume) & $\begin{array}{c}-0.02 \\
(-1.61)\end{array}$ & $\begin{array}{l}-0.02 * \\
(-1.80)\end{array}$ \\
\hline $\log ($ bond Amihud) & $\begin{array}{c}0.01 \\
(0.97)\end{array}$ & $\begin{array}{c}0.01 \\
(0.70)\end{array}$ \\
\hline Stock bid-ask spread & $\begin{array}{c}0.00 \\
(1.38)\end{array}$ & $\begin{array}{c}0.00 \\
(1.48)\end{array}$ \\
\hline LOIS & $\begin{array}{c}0.44 * * * \\
(3.03)\end{array}$ & $\begin{array}{c}0.43 * * * \\
(2.96)\end{array}$ \\
\hline$V I X^{\prime}$ & $\begin{array}{c}0.01 \\
(1.63)\end{array}$ & $\begin{array}{c}0.01 \\
(1.46)\end{array}$ \\
\hline Observations & 354,670 & 354,670 \\
\hline R-squared & 0.685 & 0.685 \\
\hline Number of firms & 459 & 459 \\
\hline
\end{tabular}

(1)

(2)

Credit rating

$77 * * *$

$91 * * *$

$(4.58)$

$-1.98$

$-1.30$

$34 * * *$

$(-2.13)$

(4.65)

0.01

$(0.26)$

$-0.02 *$ 


\section{Table 4. Effect of upfront funding cost for contracts with different maturities}

This table reports the effect of upfront funding cost $F$ on Bid-ask spread for CDS contracts with different maturities based on the North American CMA sample (January 1, 2004 to September 30, 2010). The dependent variable is Bid-ask spread. BB is a dummy variable that is 1 if the date is later than April 8, 2009, and 0 otherwise. Maturity is the maturity of CDS contracts expressed in years. All other variables are defined in Table 1. The interaction terms between $B B$ and control variables are not reported in the table. Firm-fixed effects and monthly time-fixed effects are included in all regressions. Numbers in parentheses are $t$-statistics based on standard errors that are clustered by firm and are corrected for heteroscedasticity. *, **, and *** denote statistical significance at the $10 \%, 5 \%$, and $1 \%$ level, respectively.

\begin{tabular}{|c|c|c|c|c|c|}
\hline & $\begin{array}{l}(1) \\
1 \mathrm{Y}\end{array}$ & $\begin{array}{l}(2) \\
3 Y\end{array}$ & $\begin{array}{l}(3) \\
7 Y\end{array}$ & $\begin{array}{l}(4) \\
10 \mathrm{Y}\end{array}$ & $\begin{array}{c}\text { (5) } \\
\text { All Maturities }\end{array}$ \\
\hline$F$ & $\begin{array}{c}3.66 * * * \\
(3.72)\end{array}$ & $\begin{array}{l}-0.80 \\
(-1.36)\end{array}$ & $\begin{array}{c}1.63 * * * \\
(4.94)\end{array}$ & $\begin{array}{c}2.25 * * * \\
(5.47)\end{array}$ & $\begin{array}{c}0.83 * * * \\
(6.91)\end{array}$ \\
\hline$F X B B$ & $\begin{array}{c}-2.96 \\
(-0.54)\end{array}$ & $\begin{array}{l}2.67^{*} \\
(1.84)\end{array}$ & $\begin{array}{c}3.92 * * * \\
(2.82)\end{array}$ & $\begin{array}{c}4.16 * * \\
(2.16)\end{array}$ & $\begin{array}{c}-1.12 \\
(-1.39)\end{array}$ \\
\hline$F X B B X$ Maturity & & & & & $\begin{array}{c}0.93 * * * \\
(6.68)\end{array}$ \\
\hline Maturity & & & & & $\begin{array}{c}-0.08 * * * \\
(-4.53)\end{array}$ \\
\hline$B B$ & $\begin{array}{l}34.78 \\
(1.58)\end{array}$ & $\begin{array}{l}6.77 * \\
(1.74)\end{array}$ & $\begin{array}{l}-3.37 \\
(-1.44)\end{array}$ & $\begin{array}{l}-3.80 \\
(-1.41)\end{array}$ & $\begin{array}{c}-4.37 * * * \\
(-3.27)\end{array}$ \\
\hline$S$ & $\begin{array}{c}0.07 * * * \\
(13.11)\end{array}$ & $\begin{array}{c}0.04 * * * \\
(17.02)\end{array}$ & $\begin{array}{c}0.03 * * * \\
(18.29)\end{array}$ & $\begin{array}{l}0.02 * * * \\
(16.99)\end{array}$ & $\begin{array}{l}0.03 * * * \\
(20.91)\end{array}$ \\
\hline Leverage & $\begin{array}{c}8.62 \\
(1.21)\end{array}$ & $\begin{array}{c}-0.11 \\
(-0.07)\end{array}$ & $\begin{array}{c}1.15 \\
(0.99)\end{array}$ & $\begin{array}{c}1.22 \\
(0.81)\end{array}$ & $\begin{array}{c}2.22 * * \\
(2.02)\end{array}$ \\
\hline Stock volatility & $\begin{array}{l}39.66^{*} \\
(1.89)\end{array}$ & $\begin{array}{c}28.63 * * * \\
(4.04)\end{array}$ & $\begin{array}{c}30.58 * * * \\
(5.46)\end{array}$ & $\begin{array}{c}33.16 * * * \\
(5.25)\end{array}$ & $\begin{array}{c}37.00 * * * \\
(9.81)\end{array}$ \\
\hline Log(stock volume) & $\begin{array}{c}0.63 \\
(0.99)\end{array}$ & $\begin{array}{c}-0.00 \\
(-0.03)\end{array}$ & $\begin{array}{l}-0.14 * \\
(-1.76)\end{array}$ & $\begin{array}{l}-0.18^{*} \\
(-1.77)\end{array}$ & $\begin{array}{c}0.17 * * \\
(1.98)\end{array}$ \\
\hline Log(bond volume) & $\begin{array}{l}0.34 * * \\
(2.66)\end{array}$ & $\begin{array}{c}0.01 \\
(0.50)\end{array}$ & $\begin{array}{l}-0.03 * \\
(-1.77)\end{array}$ & $\begin{array}{c}-0.01 \\
(-0.73)\end{array}$ & $\begin{array}{c}-0.02 \\
(-1.50)\end{array}$ \\
\hline $\log ($ bond Amihud) & $\begin{array}{c}0.04 \\
(0.27)\end{array}$ & $\begin{array}{c}0.00 \\
(0.25)\end{array}$ & $\begin{array}{l}-0.02 * \\
(-1.81)\end{array}$ & $\begin{array}{c}-0.02 \\
(-1.04)\end{array}$ & $\begin{array}{c}-0.01 \\
(-0.49)\end{array}$ \\
\hline Stock bid-ask spread & $\begin{array}{c}-0.01 \\
(-0.79)\end{array}$ & $\begin{array}{c}0.00 \\
(1.24)\end{array}$ & $\begin{array}{c}0.00 \\
(0.88)\end{array}$ & $\begin{array}{c}0.00 \\
(0.35)\end{array}$ & $\begin{array}{c}0.01 * * * \\
(5.05)\end{array}$ \\
\hline$L O I S$ & $\begin{array}{c}0.01 \\
(0.00)\end{array}$ & $\begin{array}{c}1.15 \\
(1.11)\end{array}$ & $\begin{array}{c}0.07 \\
(0.13)\end{array}$ & $\begin{array}{l}-1.29 * * \\
(-2.13)\end{array}$ & $\begin{array}{c}-0.45 * * * \\
(-2.62)\end{array}$ \\
\hline$V I X^{\prime}$ & $\begin{array}{c}-0.05 \\
(-0.48)\end{array}$ & $\begin{array}{c}-0.03 * * \\
(-2.01)\end{array}$ & $\begin{array}{c}0.01 \\
(0.63)\end{array}$ & $\begin{array}{c}0.01 \\
(0.75)\end{array}$ & $\begin{array}{c}-0.01 * * \\
(-2.40)\end{array}$ \\
\hline $\begin{array}{l}\text { Observations } \\
\text { R-squared } \\
\text { Number of firms }\end{array}$ & $\begin{array}{c}10,346 \\
0.692 \\
34 \\
\end{array}$ & $\begin{array}{c}86,402 \\
0.688 \\
274 \\
\end{array}$ & $\begin{array}{c}103,535 \\
0.689 \\
300\end{array}$ & $\begin{array}{c}77,649 \\
0.620 \\
261 \\
\end{array}$ & $\begin{array}{c}680,820 \\
0.496 \\
462 \\
\end{array}$ \\
\hline
\end{tabular}




\section{Table 5. Central clearing}

This table reports the effect of central clearing on Bid-ask spread based on the North American Markit sample. The sample period for this test is from April 1, 2010 to September 14, 2014. The dependent variable is Bid-ask spread. $F^{\text {Markit }}$ is the upfront funding cost as defined in Equation (4). Clear is a dummy variable, which is equal to 1 if a CDS contract is centrally cleared, 0 otherwise. All other variables are defined in Table 1. Column (1) is based on the overall sample. Column (2) is based on the CDS contracts that initiated central clearing between April 1, 2010 and September 14, 2014. Firm-fixed effects and monthly time-fixed effects are included in all regressions. Numbers in parentheses are $t$-statistics based on standard errors that are clustered by firm and are corrected for heteroscedasticity. *, **, and *** denote statistical significance at the $10 \%, 5 \%$, and $1 \%$ level, respectively.

\begin{tabular}{|c|c|c|}
\hline & $\begin{array}{c}\text { (1) } \\
\text { Overall sample }\end{array}$ & $\begin{array}{c}(2) \\
\text { Cleared sample }\end{array}$ \\
\hline$F^{\text {Markit }}$ & $\begin{array}{c}0.59 * * * \\
(4.63)\end{array}$ & $\begin{array}{c}0.83 * * * \\
(5.28)\end{array}$ \\
\hline$F^{\text {Markit }}$ X Clear & $\begin{array}{c}-0.41 * * \\
(-2.46)\end{array}$ & $\begin{array}{c}-0.69 * * * \\
(-3.40)\end{array}$ \\
\hline Clear & $\begin{array}{l}-0.38 * * \\
(-2.00)\end{array}$ & $\begin{array}{c}0.31 \\
(1.31)\end{array}$ \\
\hline$S$ & $\begin{array}{l}0.04 * * * \\
(31.19)\end{array}$ & $\begin{array}{c}0.04 * * * \\
(27.03)\end{array}$ \\
\hline Leverage & $\begin{array}{l}-1.21 \\
(-1.01)\end{array}$ & $\begin{array}{l}-1.82 \\
(-1.09)\end{array}$ \\
\hline Stock volatility & $\begin{array}{c}15.21 * * * \\
(3.77)\end{array}$ & $\begin{array}{c}15.92 * * * \\
(2.74)\end{array}$ \\
\hline Log(stock volume) & $\begin{array}{l}-0.00 \\
(-0.07)\end{array}$ & $\begin{array}{c}0.08 \\
(1.04)\end{array}$ \\
\hline Log(bond volume) & $\begin{array}{c}-0.03 * * * \\
(-3.02)\end{array}$ & $\begin{array}{c}-0.06 * * * \\
(-4.04)\end{array}$ \\
\hline $\log ($ bond Amihud $)$ & $\begin{array}{l}-0.00 \\
(-0.09)\end{array}$ & $\begin{array}{l}-0.01 \\
(-1.16)\end{array}$ \\
\hline Stock bid-ask spread & $\begin{array}{c}-0.04 \\
(-1.61)\end{array}$ & $\begin{array}{l}-0.05 \\
(-1.21)\end{array}$ \\
\hline LOIS & $\begin{array}{c}3.48 * * * \\
(5.91)\end{array}$ & $\begin{array}{c}3.70 * * * \\
(4.07)\end{array}$ \\
\hline$V I X^{\prime}$ & $\begin{array}{c}0.03^{* * * *} \\
(7.58)\end{array}$ & $\begin{array}{c}0.03^{* * *} \\
(5.38)\end{array}$ \\
\hline Observations & 240,122 & 96,355 \\
\hline R-squared & 0.630 & 0.731 \\
\hline Number of firms & 347 & 109 \\
\hline
\end{tabular}




\section{Table 6. Deutsche Bank's exit from the CDS market}

This table reports the effect of the Deutsche Bank's exit from the single-name CDS market on bid-ask spreads based on the North American Markit sample (April 1, 2010 to October 19, 2016). The dependent variable is Bid-ask spread. $D B$ is a dummy variable that is 1 if the date is after Deutsche Bank exits the single-name CDS market, and 0 otherwise. The exit date is chosen to be September 15, 2014 and November 17, 2014 in columns (1) and (2), respectively. Clear is a dummy variable, which is equal to 1 if a CDS contract is centrally cleared, 0 otherwise. All other variables are defined in Table 1. Interaction terms between $D B$ and control variables are not reported in the table. Firm-fixed effects and monthly time-fixed effects are included in all regressions. Numbers in parentheses are $t$-statistics based on standard errors that are clustered by firm and are corrected for heteroscedasticity. $*$, **, and *** denote statistical significance at the $10 \%, 5 \%$, and $1 \%$ level, respectively.

\begin{tabular}{|c|c|c|}
\hline VARIABLES & $\begin{array}{c}(1) \\
09 / 15 / 2014 \\
\end{array}$ & $\begin{array}{c}(2) \\
11 / 17 / 2014 \\
\end{array}$ \\
\hline$F^{\text {Markit }}$ & $\begin{array}{c}0.70^{* * * *} \\
(5.14)\end{array}$ & $\begin{array}{c}0.70 * * * \\
(5.11)\end{array}$ \\
\hline$F^{\text {Markit }} X D B$ & $\begin{array}{c}0.83^{* * * *} \\
(3.33)\end{array}$ & $\begin{array}{c}0.80 * * * \\
(3.28)\end{array}$ \\
\hline$D B$ & $\begin{array}{l}5.14^{*} \\
(1.85)\end{array}$ & $\begin{array}{l}5.40 * \\
(1.79)\end{array}$ \\
\hline$F^{\text {Markit }} X$ Clear & $\begin{array}{c}-0.57 * * * \\
(-2.97)\end{array}$ & $\begin{array}{c}-0.54 * * * \\
(-2.88)\end{array}$ \\
\hline Clear & $\begin{array}{l}-0.41^{*} \\
(-1.65)\end{array}$ & $\begin{array}{l}-0.40 \\
(-1.64)\end{array}$ \\
\hline$S$ & $\begin{array}{c}0.04 * * * \\
(33.81)\end{array}$ & $\begin{array}{c}0.04 * * * * \\
(33.94)\end{array}$ \\
\hline Leverage & $\begin{array}{l}-2.45^{*} \\
(-1.78)\end{array}$ & $\begin{array}{l}-2.46^{*} \\
(-1.80)\end{array}$ \\
\hline Stock volatility & $\begin{array}{c}4.65 \\
(0.90)\end{array}$ & $\begin{array}{c}5.63 \\
(1.12)\end{array}$ \\
\hline Log(stock volume) & $\begin{array}{c}0.26^{* * * *} \\
(3.33)\end{array}$ & $\begin{array}{c}0.27 * * * \\
(3.46)\end{array}$ \\
\hline Log(bond volume) & $\begin{array}{c}0.00 \\
(0.03)\end{array}$ & $\begin{array}{l}-0.00 \\
(-0.04)\end{array}$ \\
\hline $\log ($ bond Amihud $)$ & $\begin{array}{l}0.04 * * \\
(2.03)\end{array}$ & $\begin{array}{c}0.04 * * \\
(2.14)\end{array}$ \\
\hline Stock bid-ask spread & $\begin{array}{l}-0.03 \\
(-0.95)\end{array}$ & $\begin{array}{l}-0.03 \\
(-0.92)\end{array}$ \\
\hline LOIS & $\begin{array}{c}3.33 * * * \\
(5.58)\end{array}$ & $\begin{array}{c}3.37 * * * * \\
(5.67)\end{array}$ \\
\hline$V I X^{\prime}$ & $\begin{array}{c}0.02 * * * \\
(5.89)\end{array}$ & $\begin{array}{c}0.03^{* * * *} \\
(6.35)\end{array}$ \\
\hline $\begin{array}{l}\text { Observations } \\
\text { R-squared } \\
\text { Number of firms }\end{array}$ & $\begin{array}{c}333,401 \\
0.649 \\
361\end{array}$ & $\begin{array}{c}333,401 \\
0.649 \\
361\end{array}$ \\
\hline
\end{tabular}




\section{Table 7. Analyses using the CDS Small Bang}

Panel A reports the effect of upfront funding cost $F$ on Bid-ask spread using the European CMA sample (April 1, 2004 to September 30, 2010). The dependent variable is Bid-ask spread. SB is a dummy variable which is equal to 1 if the date is later than June 20,2009, and 0 otherwise. Small is a dummy variable that is 1 if the reference entity's asset is below the median, and 0 otherwise. Speculative is a dummy variable that is 1 if the reference entity's credit rating is below BBB, and 0 otherwise. Panel B reports the effect of upfront funding cost $F$ on Bid-ask spread for CDS contracts with different maturities using the European CMA sample (January 1, 2004 to September 30, 2010). Maturity is the maturity of CDS contracts expressed in years. Panel $\mathrm{C}$ reports the effects of central clearing and the event of Deutsche Bank's exit from the single-name CDS market based on the European Markit sample on bid-ask spreads. The sample period for central clearing is from April 1, 2010 to September 14, 2014. Clear is a dummy variable, which is equal to 1 if a CDS contract is centrally cleared, 0 otherwise. The sample period for the event of Deutsche Bank's exit is from April 1, 2010 to October 19, 2016. The exit date is chosen to be September 15, 2014 and November 17, 2014 in columns (1) and (2), respectively. $D B$ is a dummy variable that is 1 if the date is after the exit date, and 0 otherwise. $F^{\text {Markit }}$ is the upfront funding cost as defined in Equation (4). All other variables are defined in Table 1. Interaction terms between $S B$ or $D B$ and control variables are not reported in the table. Firm-fixed effects and monthly time-fixed effects are included in all regressions. Numbers in parentheses are $t$-statistics based on standard errors that are clustered by firm and are corrected for heteroscedasticity. $*$, **, and *** denote statistical significance at the $10 \%, 5 \%$, and $1 \%$ level, respectively. 
Panel A: Effect of upfront funding cost for firms with different sizes and credit ratings

\begin{tabular}{|c|c|c|c|c|}
\hline & $(1)$ & $(2)$ & (3) & (4) \\
\hline$F$ & $\begin{array}{c}1.65^{* * * *} \\
(5.96)\end{array}$ & $\begin{array}{c}1.87 * * * \\
(5.79)\end{array}$ & $\begin{array}{c}2.05 * * * \\
(6.87)\end{array}$ & $\begin{array}{c}2.29 * * * \\
(6.13)\end{array}$ \\
\hline$F X S B$ & $\begin{array}{c}3.61 * * * \\
(3.48)\end{array}$ & $\begin{array}{c}3.69^{* * * *} \\
(3.24)\end{array}$ & $\begin{array}{c}2.43 * * \\
(2.41)\end{array}$ & $\begin{array}{l}1.93 * * \\
(1.99)\end{array}$ \\
\hline$S B$ & $\begin{array}{c}-0.25 \\
(-0.57)\end{array}$ & $\begin{array}{c}-0.60 \\
(-1.00)\end{array}$ & $\begin{array}{l}-1.10^{* *} \\
(-2.22)\end{array}$ & $\begin{array}{c}-1.77 * * * \\
(-2.75)\end{array}$ \\
\hline$F X S B X$ Small & & & $\begin{array}{l}4.31 * * \\
(2.02)\end{array}$ & \\
\hline$F X S B X$ Speculative & & & & $\begin{array}{c}5.13 * * \\
(1.97)\end{array}$ \\
\hline$S$ & $\begin{array}{c}0.04 * * * \\
(27.35)\end{array}$ & $\begin{array}{c}0.04^{* * * *} \\
(23.80)\end{array}$ & $\begin{array}{c}0.03 * * * \\
(23.16)\end{array}$ & $\begin{array}{r}0.03 * * * \\
(19.22)\end{array}$ \\
\hline Stock bid-ask spread & & $\begin{array}{c}0.59 \\
(0.11)\end{array}$ & $\begin{array}{c}-2.87 \\
(-0.55)\end{array}$ & $\begin{array}{c}-3.40 \\
(-0.86)\end{array}$ \\
\hline Log(stock volume) & & $\begin{array}{c}0.08 \\
(0.78)\end{array}$ & $\begin{array}{c}0.11 \\
(1.08)\end{array}$ & $\begin{array}{c}0.05 \\
(0.64)\end{array}$ \\
\hline VSTOXX & $\begin{array}{c}0.03^{* * * *} \\
(8.49)\end{array}$ & $\begin{array}{c}0.03^{* * * *} \\
(6.94)\end{array}$ & $\begin{array}{c}0.03 * * * \\
(4.24)\end{array}$ & $\begin{array}{c}0.00 \\
(0.24)\end{array}$ \\
\hline LOIS Euro & $\begin{array}{c}0.81^{* * * *} \\
(3.85)\end{array}$ & $\begin{array}{c}0.77 * * * \\
(3.15)\end{array}$ & $\begin{array}{c}0.33 \\
(1.51)\end{array}$ & $\begin{array}{c}1.23 * * * \\
(3.99)\end{array}$ \\
\hline Observations & 425,410 & 281,947 & 281,947 & 281,947 \\
\hline R-squared & 0.706 & 0.719 & 0.725 & 0.686 \\
\hline Number of firms & 401 & 271 & 271 & 271 \\
\hline
\end{tabular}


Panel B: Effect of upfront funding cost for contracts with different maturities

\begin{tabular}{|c|c|c|c|c|c|}
\hline & (1) & (2) & (3) & (4) & (5) \\
\hline & $1 \mathrm{Y}$ & $3 Y$ & $7 \mathrm{Y}$ & $10 \mathrm{Y}$ & All Maturities \\
\hline \multirow[t]{2}{*}{$F$} & 0.53 & 0.31 & 0.94 & 1.31 & $1.84 * * *$ \\
\hline & $(0.12)$ & $(0.20)$ & $(0.84)$ & $(1.64)$ & $(6.31)$ \\
\hline \multirow[t]{2}{*}{$F X S B$} & 0.29 & 3.19 & $4.17 * *$ & $5.57 * * *$ & -0.85 \\
\hline & $(0.03)$ & $(1.26)$ & $(2.24)$ & $(2.67)$ & $(-0.47)$ \\
\hline \multirow[t]{2}{*}{$F X S B X$ Maturity } & & & & & $0.84 * * *$ \\
\hline & & & & & $(2.90)$ \\
\hline \multirow[t]{2}{*}{ Maturity } & & & & & $-0.43 * * *$ \\
\hline & & & & & $(-12.69)$ \\
\hline \multirow[t]{2}{*}{$S B$} & 7.38 & $2.71 * * *$ & -1.37 & 1.44 & $-1.15^{* * *}$ \\
\hline & $(0.74)$ & $(2.83)$ & $(-1.01)$ & $(1.45)$ & $(-2.79)$ \\
\hline \multirow[t]{2}{*}{$S$} & $0.12 * * *$ & $0.04 * * *$ & $0.05^{* * *}$ & $0.04 * * *$ & $0.04 * * *$ \\
\hline & $(7.02)$ & $(6.50)$ & $(17.26)$ & $(21.16)$ & $(28.15)$ \\
\hline \multirow[t]{2}{*}{ Stock bid-ask spread } & -3.00 & 0.23 & 0.71 & 7.43 & 3.92 \\
\hline & $(-0.10)$ & $(0.05)$ & $(0.14)$ & $(0.98)$ & $(0.86)$ \\
\hline \multirow[t]{2}{*}{ Log(stock volume $)$} & -0.52 & -0.03 & -0.02 & $-0.14 *$ & 0.00 \\
\hline & $(-1.17)$ & $(-0.56)$ & $(-0.19)$ & $(-1.74)$ & $(0.06)$ \\
\hline \multirow[t]{2}{*}{ VSTOXX } & 0.07 & $0.05 * * *$ & $0.05 * * *$ & $0.06 * * *$ & $0.13 * * *$ \\
\hline & $(0.69)$ & $(3.95)$ & $(2.92)$ & $(4.25)$ & (13.62) \\
\hline \multirow[t]{2}{*}{ LOIS Euro } & -4.37 & $1.81 * *$ & $1.63^{*}$ & $2.17 * * *$ & 0.00 \\
\hline & $(-0.80)$ & $(2.19)$ & $(1.86)$ & $(5.28)$ & $(0.02)$ \\
\hline Observations & 14,926 & 36,058 & 50,461 & 66,740 & 524,331 \\
\hline R-squared & 0.756 & 0.625 & 0.710 & 0.628 & 0.676 \\
\hline Number of firms & 218 & 285 & 285 & 315 & 379 \\
\hline
\end{tabular}


Panel C: Effect of central clearing and Deutsche Bank's exit from the CDS Market

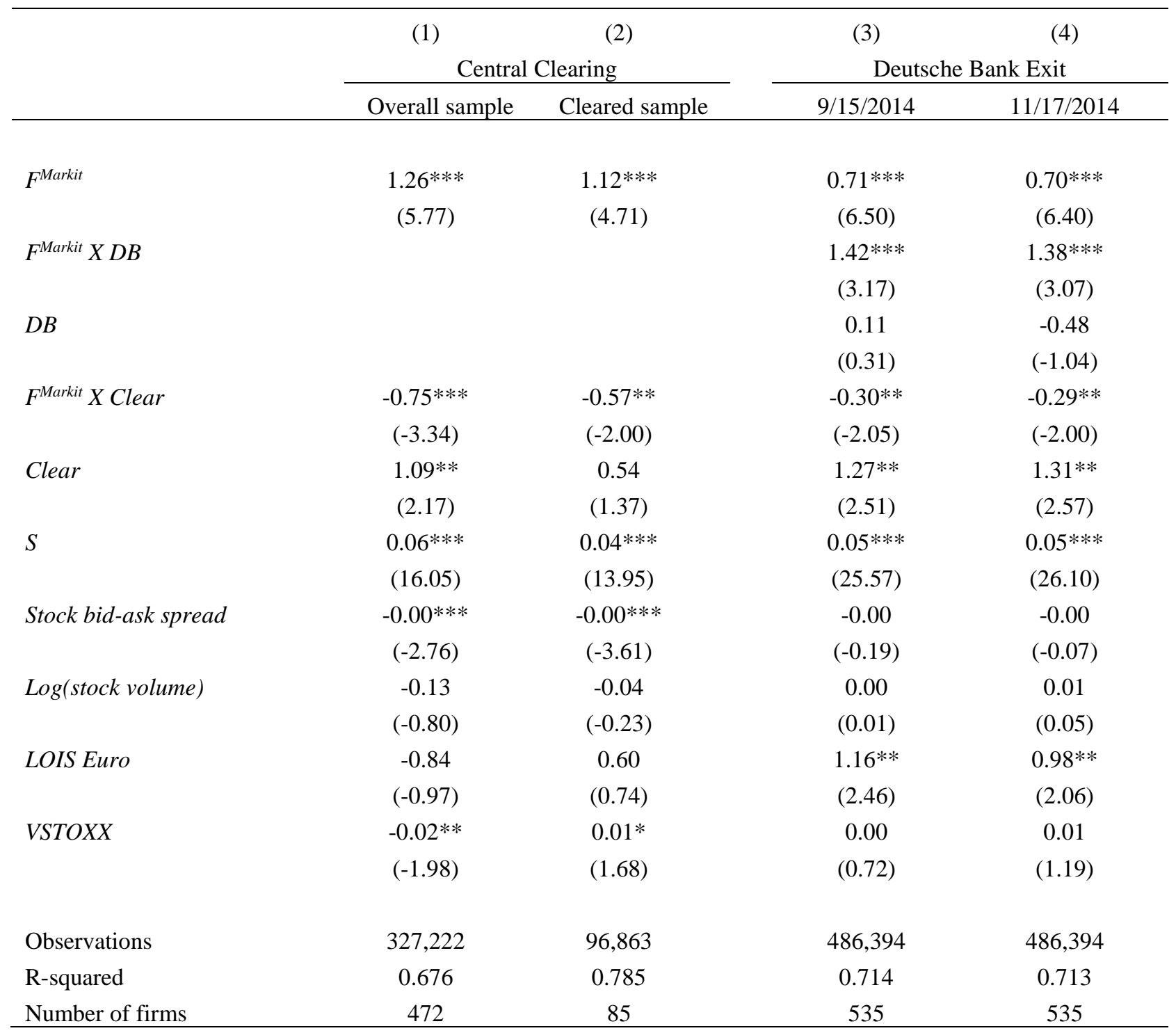


Table 8. Effects of upfront funding cost around the CDS Big Bang using European CDSs as a control group

This table reports the effect of upfront funding cost $F$ on Bid-ask spread using a combined sample of CDSs on North American and European firms. The North American sample is from our North American CMA sample and the European Sample is from our European CMA sample. The dependent variable is Bid-ask spread. BB is a dummy variable that is 1 if the date is later than April 8, 2009, and 0 otherwise. $N A$ is a dummy variable, which is equal to 1 if an observation is for a North American firm, and 0 otherwise. Column (1) is based on the actual date for the CDS Big Bang, while columns (2) and (3) are based on two fictitious dates for the event, 2/8/2009 and 8/20/2009, respectively. All other variables are defined in Table 1. Firm-fixed effects and monthly time-fixed effects are included in all regressions. Numbers in parentheses are $t$-statistics based on standard errors that are clustered by firm and are corrected for heteroscedasticity. $*, * *$, and $* * *$ denote statistical significance at the $10 \%, 5 \%$, and $1 \%$ level, respectively.

\begin{tabular}{|c|c|c|c|}
\hline & (1) & (2) & (3) \\
\hline & Baseline test & Placebo test 1 & Placebo test 2 \\
\hline Event date & 04/08/2009 & 02/08/2009 & 08/20/2009 \\
\hline Sample period & 1/25/2009-6/19/2009 & $12 / 8 / 2008-4 / 7 / 2009$ & $6 / 20 / 2009-10 / 20 / 2009$ \\
\hline \multirow[t]{2}{*}{$F$} & $0.78^{* * *}$ & $0.94 * * *$ & $2.57 * * *$ \\
\hline & $(3.14)$ & $(4.26)$ & $(4.08)$ \\
\hline \multirow[t]{2}{*}{$F \times B B$} & 0.45 & -0.20 & -0.43 \\
\hline & $(0.92)$ & $(-0.44)$ & $(-0.42)$ \\
\hline \multirow[t]{2}{*}{$F \times B B \times N A$} & $1.66^{* * *}$ & 0.05 & 0.61 \\
\hline & $(2.61)$ & $(0.10)$ & $(0.52)$ \\
\hline \multirow[t]{2}{*}{$B B \times N A$} & 0.27 & $2.10^{* * *}$ & $1.17^{* * *}$ \\
\hline & $(0.97)$ & $(6.81)$ & $(4.56)$ \\
\hline \multirow[t]{2}{*}{$B B$} & -0.30 & $-1.23 * * *$ & $-0.74 * * *$ \\
\hline & $(-1.23)$ & $(-4.84)$ & $(-3.20)$ \\
\hline \multirow[t]{2}{*}{$S$} & $0.02 * * *$ & $0.03 * * *$ & $0.02^{* * *}$ \\
\hline & (14.54) & $(15.62)$ & $(7.72)$ \\
\hline \multirow[t]{2}{*}{ VSTOXX } & $-0.03 * * *$ & $-0.10 * * *$ & -0.02 \\
\hline & $(-2.97)$ & $(-9.96)$ & $(-1.10)$ \\
\hline \multirow[t]{2}{*}{$V I X^{\prime}$} & 0.01 & $-0.02 * * *$ & 0.01 \\
\hline & (1.63) & $(-2.65)$ & $(0.32)$ \\
\hline \multirow[t]{2}{*}{ LOIS Euro } & -0.69 & $4.23 * * *$ & $-1.61^{* *}$ \\
\hline & $(-1.60)$ & $(8.48)$ & $(-2.01)$ \\
\hline \multirow[t]{2}{*}{ LOIS } & $4.43^{* * *}$ & 0.24 & $4.55^{* * * *}$ \\
\hline & $(9.06)$ & $(1.03)$ & $(4.14)$ \\
\hline Observations & 58,043 & 43,883 & 54,770 \\
\hline R-squared & 0.246 & 0.246 & 0.229 \\
\hline Number of firms & 731 & 672 & 753 \\
\hline
\end{tabular}




\section{Table 9. Robustness checks: CDS-Bond basis and CDS volatility}

This table reports the effect of upfront funding cost $F$ on the absolute value of CDS-bond basis and CDS volatility, based on the CMA sample (January 1, 2004 to September 30, 2010). The dependent variable is $A B S$ (basis) in columns (1) and (2), CDS volatility (level) and CDS volatility (change) in columns (3) and (4), respectively. $A B S$ (basis) is the absolute value of CDS-bond basis, which is defined as the CDS spread minus the bond yield spread of the reference entity, in bps. CDS volatility (level) is the two-week rolling standard deviation of CDS spreads, in bps. CDS volatility (change) is the two-week rolling standard deviation of changes in CDS spreads, in bps. Pay is a dummy variable that is 1 if basis arbitrageurs pay the upfront fee, and 0 otherwise, as defined in Equations (5) and (6). $B B$ is a dummy variable that is 1 if the date is later than April 8, 2009, and 0 otherwise. All other variables are defined in Table 1. The interaction terms between control variables and $B B$ or Pay are not reported in the table. Firm-fixed effects

and monthly time-fixed effects are included in all regressions. Numbers in parentheses are $t$-statistics based on standard errors that are clustered by firm and are corrected for heteroscedasticity. *, **, and *** denote statistical significance at the $10 \%, 5 \%$, and $1 \%$ level, respectively. 


\begin{tabular}{|c|c|c|c|c|}
\hline & $\begin{array}{c}(1) \\
\text { ABS(basis) }\end{array}$ & $\begin{array}{c}(2) \\
\text { ABS(basis) }\end{array}$ & $\begin{array}{c}(3) \\
\text { CDS volatility } \\
\text { (level) }\end{array}$ & $\begin{array}{c}(4) \\
\text { CDS volatility } \\
\text { (change) }\end{array}$ \\
\hline$F$ & $\begin{array}{l}-6.38^{*} \\
(-1.76)\end{array}$ & $\begin{array}{c}-8.22 * * \\
(-2.20)\end{array}$ & $\begin{array}{c}0.93 * * * \\
(5.74)\end{array}$ & $\begin{array}{c}0.30 * * * \\
(3.18)\end{array}$ \\
\hline$F X B B$ & $\begin{array}{c}37.79 * * * * \\
(4.10)\end{array}$ & $\begin{array}{c}26.92 * * * * \\
(2.59)\end{array}$ & $\begin{array}{c}2.92 * * * * \\
(4.31)\end{array}$ & $\begin{array}{c}2.12^{* * * *} \\
(5.77)\end{array}$ \\
\hline$B B$ & $\begin{array}{c}8.37 \\
(0.27)\end{array}$ & $\begin{array}{l}26.86 \\
(0.77)\end{array}$ & $\begin{array}{l}-1.83 \\
(-1.32)\end{array}$ & $\begin{array}{l}-0.47 \\
(-0.56)\end{array}$ \\
\hline$F \times B B \times P a y$ & & $\begin{array}{l}21.71^{*} \\
(1.94)\end{array}$ & & \\
\hline Pay & & $\begin{array}{l}-16.96 \\
(-1.01)\end{array}$ & & \\
\hline$B B \times P a y$ & & $\begin{array}{l}-63.24 * \\
(-1.66)\end{array}$ & & \\
\hline$F \times$ Pay & & $\begin{array}{c}2.81 \\
(0.79)\end{array}$ & & \\
\hline$S$ & $\begin{array}{l}0.05^{* *} \\
(2.26)\end{array}$ & $\begin{array}{l}0.04 * * \\
(2.05)\end{array}$ & $\begin{array}{l}0.04 * * * * \\
(39.36)\end{array}$ & $\begin{array}{l}0.03 * * * \\
(39.92)\end{array}$ \\
\hline Leverage & $\begin{array}{l}26.28 \\
(1.14)\end{array}$ & $\begin{array}{l}21.24 \\
(0.93)\end{array}$ & $\begin{array}{c}-1.74 * * \\
(-1.99)\end{array}$ & $\begin{array}{l}-1.01^{*} \\
(-1.77)\end{array}$ \\
\hline Stock volatility & $\begin{array}{l}123.79 \\
(1.34)\end{array}$ & $\begin{array}{c}215.97 * * \\
(2.50)\end{array}$ & $\begin{array}{c}108.85^{* * *} \\
(14.78)\end{array}$ & $\begin{array}{c}84.57 * * * \\
(17.44)\end{array}$ \\
\hline Log(stock volume) & $\begin{array}{l}-1.02 \\
(-0.71)\end{array}$ & $\begin{array}{l}-1.80 \\
(-1.15)\end{array}$ & $\begin{array}{c}0.60 * * * \\
(7.97)\end{array}$ & $\begin{array}{c}0.24 * * * \\
(4.97)\end{array}$ \\
\hline Log(bond volume) & $\begin{array}{c}-1.28 * * * \\
(-3.61)\end{array}$ & $\begin{array}{c}-1.53 * * * \\
(-3.50)\end{array}$ & $\begin{array}{c}0.13^{* * * *} \\
(8.69)\end{array}$ & $\begin{array}{c}0.07 * * * \\
(7.69)\end{array}$ \\
\hline $\log ($ bond Amihud $)$ & $\begin{array}{c}1.01 * * * \\
(3.29)\end{array}$ & $\begin{array}{c}0.97 * * * \\
(2.90)\end{array}$ & $\begin{array}{c}0.03 * * * \\
(2.90)\end{array}$ & $\begin{array}{l}0.02 * * \\
(2.22)\end{array}$ \\
\hline Stock bid-ask spread & $\begin{array}{c}0.14^{* * *} \\
(3.17)\end{array}$ & $\begin{array}{l}0.11 * * \\
(2.50)\end{array}$ & $\begin{array}{c}0.00 \\
(1.50)\end{array}$ & $\begin{array}{c}0.00 \\
(0.77)\end{array}$ \\
\hline LOIS & $\begin{array}{c}21.60 * * * * \\
(5.96)\end{array}$ & $\begin{array}{c}23.20 * * * \\
(5.89)\end{array}$ & $\begin{array}{c}1.66^{* * * *} \\
(5.87)\end{array}$ & $\begin{array}{c}1.22 * * * \\
(7.31)\end{array}$ \\
\hline$V I X^{\prime}$ & $\begin{array}{c}0.66 * * * \\
(7.22)\end{array}$ & $\begin{array}{c}0.34 * * \\
(2.06)\end{array}$ & $\begin{array}{c}0.03 * * * * \\
(3.13)\end{array}$ & $\begin{array}{c}0.03 * * * \\
(6.33)\end{array}$ \\
\hline $\begin{array}{l}\text { Observations } \\
\text { R-squared } \\
\text { Number of firms }\end{array}$ & $\begin{array}{c}234,692 \\
0.476 \\
405\end{array}$ & $\begin{array}{c}234,692 \\
0.481 \\
405\end{array}$ & $\begin{array}{c}354,670 \\
0.536 \\
459\end{array}$ & $\begin{array}{c}354,651 \\
0.596 \\
459\end{array}$ \\
\hline
\end{tabular}




\section{Table 10. Robustness checks: alternative identification specification}

This table reports the effect of upfront payment DIS on Bid-ask spread based on the North American CMA sample (January 1, 2004 to September 30, 2010). The dependent variable is Bid-ask spread. BB is a dummy variable that is 1 if the date is later than April 8, 2009, and 0 otherwise. All other variables are defined in Table 1. Interaction terms between $B B$ and control variables and the coefficients of a quintic polynomial in CDS spreads are not reported in the table. Firm-fixed effects and monthly time-fixed effects are included in all regressions. Numbers in parentheses are $t$-statistics based on standard errors that are clustered by firm and are corrected for heteroscedasticity. $*, * *$, and $* * *$ denote statistical significance at the $10 \%, 5 \%$, and $1 \%$ level, respectively.

\begin{tabular}{|c|c|c|c|c|}
\hline & $\begin{array}{c}(1) \\
\text { Pre-BB }\end{array}$ & $\begin{array}{c}(2) \\
\text { Post-BB }\end{array}$ & $\begin{array}{c}(3) \\
\text { Pre and Post-BB } \\
\end{array}$ & $\begin{array}{c}\text { (4) } \\
\text { Pre and Post-BB } \\
\end{array}$ \\
\hline$D I S$ & $\begin{array}{l}-0.21 \\
(-0.69)\end{array}$ & $\begin{array}{c}1.81 * * * \\
(3.27)\end{array}$ & $\begin{array}{l}-0.21 \\
(-0.65)\end{array}$ & $\begin{array}{l}-0.20 \\
(-0.64)\end{array}$ \\
\hline$D I S X B B$ & & & $\begin{array}{l}1.91 * * \\
(2.50)\end{array}$ & $\begin{array}{l}1.46^{*} \\
(1.80)\end{array}$ \\
\hline$D I S X B B X L O I S$ & & & & $\begin{array}{c}1.75^{* * *} \\
(3.73)\end{array}$ \\
\hline$B B$ & & & $\begin{array}{l}-9.04 * \\
(-1.91)\end{array}$ & $\begin{array}{l}-8.20 * \\
(-1.72)\end{array}$ \\
\hline$S$ & $\begin{array}{c}0.03 \\
(0.91)\end{array}$ & $\begin{array}{c}0.07 \\
(0.90)\end{array}$ & $\begin{array}{c}0.02 \\
(0.59)\end{array}$ & $\begin{array}{c}0.02 \\
(0.59)\end{array}$ \\
\hline Leverage & $\begin{array}{c}-3.07 * * * \\
(-2.74)\end{array}$ & $\begin{array}{c}0.18 \\
(0.06)\end{array}$ & $\begin{array}{c}-2.23 * * \\
(-2.43)\end{array}$ & $\begin{array}{l}-2.13 * * \\
(-2.32)\end{array}$ \\
\hline Stock volatility & $\begin{array}{c}15.59 * * * \\
(4.42)\end{array}$ & $\begin{array}{c}28.96 * * * * \\
(6.06)\end{array}$ & $\begin{array}{c}18.35^{* * * *} \\
(5.13)\end{array}$ & $\begin{array}{c}18.41 * * * \\
(5.15)\end{array}$ \\
\hline Log(stock volume) & $\begin{array}{c}0.05 \\
(0.82)\end{array}$ & $\begin{array}{l}-0.01 \\
(-0.08)\end{array}$ & $\begin{array}{c}-0.03 \\
(-0.50)\end{array}$ & $\begin{array}{c}-0.03 \\
(-0.52)\end{array}$ \\
\hline Log(bond volume) & $\begin{array}{l}-0.02 \\
(-1.35)\end{array}$ & $\begin{array}{c}-0.03 * * * \\
(-2.59)\end{array}$ & $\begin{array}{c}-0.02 \\
(-1.32)\end{array}$ & $\begin{array}{c}-0.02 \\
(-1.31)\end{array}$ \\
\hline $\log ($ bond Amihud $)$ & $\begin{array}{c}0.00 \\
(0.43)\end{array}$ & $\begin{array}{c}-0.05 * * * \\
(-3.23)\end{array}$ & $\begin{array}{c}0.00 \\
(0.33)\end{array}$ & $\begin{array}{c}0.00 \\
(0.32)\end{array}$ \\
\hline Stock bid-ask spread & $\begin{array}{c}0.00 \\
(1.61)\end{array}$ & $\begin{array}{c}0.00 \\
(0.51)\end{array}$ & $\begin{array}{c}0.00 \\
(1.28)\end{array}$ & $\begin{array}{c}0.00 \\
(1.29)\end{array}$ \\
\hline LOIS & $\begin{array}{c}0.90^{* * * *} \\
(7.15)\end{array}$ & $\begin{array}{c}2.27 * * * \\
(6.19)\end{array}$ & $\begin{array}{c}0.89^{* * * *} \\
(7.08)\end{array}$ & $\begin{array}{c}0.89 * * * \\
(7.08)\end{array}$ \\
\hline$V I X^{\prime}$ & $\begin{array}{c}0.01 \\
(1.36)\end{array}$ & $\begin{array}{c}-0.01 * * * \\
(-2.64)\end{array}$ & $\begin{array}{c}0.01 \\
(1.50)\end{array}$ & $\begin{array}{c}0.01 \\
(1.52)\end{array}$ \\
\hline Observations & 252,449 & 102,221 & 354,670 & 354,670 \\
\hline R-squared & 0.678 & 0.576 & 0.687 & 0.688 \\
\hline Number of firms & 450 & 387 & 459 & 459 \\
\hline
\end{tabular}




\section{Table 11. Robustness checks: sample construction}

Panel A reports estimates of the regressions for robustness checks for the sample construction and controls for alternative bond liquidity measures based on the North American CMA sample (January 1, 2004 to September 30, 2010). The dependent variable is Bid-ask spread. BB is a dummy variable that is 1 if the date is later than April 8, 2009, and 0 otherwise. All other variables are defined in Table 1. The interaction terms between control variables and $B B$ are not reported in the table. Firm-fixed effects and monthly time-fixed effects are included in all regressions. Numbers in parentheses are $t$-statistics based on standard errors that are clustered by firm and are corrected for heteroscedasticity. *, **, and *** denote statistical significance at the $10 \%, 5 \%$, and $1 \%$ level, respectively.

\begin{tabular}{|c|c|c|c|c|}
\hline & $\begin{array}{c}(1) \\
\text { Cutoff }=1000 \mathrm{bps}\end{array}$ & $\begin{array}{c}(2) \\
\text { Winsorized at 99\% }\end{array}$ & $\begin{array}{c}\text { (3) } \\
\text { Constant sample }\end{array}$ & $\begin{array}{c}\text { (4) } \\
\text { Bond bid-ask spread }\end{array}$ \\
\hline$F$ & $\begin{array}{c}0.89 * * * \\
(8.40)\end{array}$ & $\begin{array}{c}1.65^{* * * *} \\
(7.85)\end{array}$ & $\begin{array}{c}0.61 * * * \\
(5.68)\end{array}$ & $\begin{array}{c}0.73^{* * * *} \\
(6.02)\end{array}$ \\
\hline$F X B B$ & $\begin{array}{c}1.66^{* * * *} \\
(4.05)\end{array}$ & $\begin{array}{c}2.49 * * * \\
(4.27)\end{array}$ & $\begin{array}{c}2.36^{* * * *} \\
(6.08)\end{array}$ & $\begin{array}{c}2.26 * * * \\
(4.96)\end{array}$ \\
\hline$B B$ & $\begin{array}{l}-2.30 \\
(-1.60)\end{array}$ & $\begin{array}{c}1.27 \\
(0.57)\end{array}$ & $\begin{array}{l}-2.39 * \\
(-1.73)\end{array}$ & $\begin{array}{l}-1.92 \\
(-1.44)\end{array}$ \\
\hline$S$ & $\begin{array}{l}0.03 * * * \\
(30.09)\end{array}$ & $\begin{array}{l}0.04 * * * \\
(19.71)\end{array}$ & $\begin{array}{l}0.03 * * * \\
(27.56)\end{array}$ & $\begin{array}{l}0.03 * * * \\
(26.34)\end{array}$ \\
\hline Leverage & $\begin{array}{c}-2.49 * * \\
(-2.42)\end{array}$ & $\begin{array}{l}-4.74 * * \\
(-2.48)\end{array}$ & $\begin{array}{c}-2.18 * * \\
(-2.27)\end{array}$ & $\begin{array}{c}-1.46 \\
(-1.55)\end{array}$ \\
\hline Stock volatility & $\begin{array}{c}20.98 * * * \\
(4.95)\end{array}$ & $\begin{array}{c}16.62 * * \\
(2.02)\end{array}$ & $\begin{array}{c}14.31 * * * \\
(4.02)\end{array}$ & $\begin{array}{c}17.70 * * * \\
(4.79)\end{array}$ \\
\hline Log(stock volume) & $\begin{array}{c}0.00 \\
(0.04)\end{array}$ & $\begin{array}{l}0.23^{*} \\
(1.91)\end{array}$ & $\begin{array}{c}-0.02 \\
(-0.30)\end{array}$ & $\begin{array}{l}-0.03 \\
(-0.55)\end{array}$ \\
\hline Log(bond volume) & $\begin{array}{c}-0.02 \\
(-1.53)\end{array}$ & $\begin{array}{c}0.02 \\
(0.76)\end{array}$ & $\begin{array}{l}-0.03 * * \\
(-1.99)\end{array}$ & $\begin{array}{c}-0.02 \\
(-1.28)\end{array}$ \\
\hline $\log ($ bond Amihud $)$ & $\begin{array}{c}0.01 \\
(0.48)\end{array}$ & $\begin{array}{c}0.01 \\
(0.55)\end{array}$ & $\begin{array}{c}0.01 \\
(0.89)\end{array}$ & $\begin{array}{l}-0.00 \\
(-0.31)\end{array}$ \\
\hline Stock bid-ask spread & $\begin{array}{l}0.00^{*} \\
(1.95)\end{array}$ & $\begin{array}{l}-0.00 \\
(-0.58)\end{array}$ & $\begin{array}{c}0.00 \\
(1.05)\end{array}$ & $\begin{array}{l}0.00 * * \\
(2.49)\end{array}$ \\
\hline LOIS & $\begin{array}{l}-0.04 \\
(-0.22)\end{array}$ & $\begin{array}{c}-0.79 * * \\
(-2.56)\end{array}$ & $\begin{array}{c}0.46^{* * * *} \\
(3.18)\end{array}$ & $\begin{array}{c}0.48^{* * * *} \\
(2.96)\end{array}$ \\
\hline$V I X^{\prime}$ & $\begin{array}{l}-0.01 \\
(-1.16)\end{array}$ & $\begin{array}{c}-0.03 * * * \\
(-3.53)\end{array}$ & $\begin{array}{c}0.01 \\
(1.63)\end{array}$ & $\begin{array}{c}0.01 * * * \\
(2.90)\end{array}$ \\
\hline Bond bid-ask spread & & & & $\begin{array}{l}-0.39 * * \\
(-2.25)\end{array}$ \\
\hline Observations & 360,571 & 371,300 & 331,195 & 268,860 \\
\hline R-squared & 0.725 & 0.824 & 0.692 & 0.674 \\
\hline Number of firms & 461 & 462 & 378 & 372 \\
\hline
\end{tabular}




\section{Table 12. Overall effects of the CDS Big Bang and the CDS Small Bang}

Panel A reports the overall effect of the CDS Big Bang on Bid-ask spread based on the North American CMA sample. The sample period for columns (1) and (2) is from 3 months before to 3 months after the CDS Big Bang. The sample period for other columns is similarly defined (from 4, 5, or 6 months before to 4, 5, or 6 months after the CDS Big Bang). The dependent variable is Bid-ask spread. BB is a dummy variable that is 1 if the date is later than April 8, 2009, and 0 otherwise. Panel B reports the overall effect of the CDS Small Bang on bid-ask spreads based on the European CMA sample. $S B$ is a dummy variable which is equal to 1 if date is later than June 20, 2009, and 0 otherwise. All other variables are defined in Table 1. Firm-fixed effects are included in all regressions. Numbers in parentheses are $t$-statistics based on standard errors that are clustered by firm and are corrected for heteroscedasticity. *, **, and *** denote statistical significance at the $10 \%, 5 \%$, and $1 \%$ level, respectively.

Panel A: Overall effect of the CDS Big Bang on the bid-ask spread

\begin{tabular}{|c|c|c|c|c|c|c|c|c|}
\hline & $\begin{array}{l}(1) \\
3 \mathrm{M}\end{array}$ & $\begin{array}{l}(2) \\
3 \mathrm{M}\end{array}$ & $\begin{array}{l}(3) \\
4 \mathrm{M}\end{array}$ & $\begin{array}{l}(4) \\
4 \mathrm{M}\end{array}$ & $\begin{array}{l}(5) \\
5 \mathrm{M}\end{array}$ & $\begin{array}{l}(6) \\
5 \mathrm{M}\end{array}$ & $\begin{array}{l}(7) \\
6 \mathrm{M}\end{array}$ & $\begin{array}{l}(8) \\
6 \mathrm{M}\end{array}$ \\
\hline$B B$ & $\begin{array}{c}-0.62 * * * \\
(-3.17)\end{array}$ & $\begin{array}{l}0.34 * * \\
(2.08)\end{array}$ & $\begin{array}{c}-1.23 * * * \\
(-7.40)\end{array}$ & $\begin{array}{c}-0.03 \\
(-0.19)\end{array}$ & $\begin{array}{c}-1.76 * * * \\
(-9.39)\end{array}$ & $\begin{array}{c}-0.47 * * * \\
(-2.96)\end{array}$ & $\begin{array}{c}-2.14 * * * \\
(-11.60)\end{array}$ & $\begin{array}{c}-0.72 * * * * \\
(-4.78)\end{array}$ \\
\hline$F \times B B$ & $\begin{array}{c}1.35^{* * *} * \\
(4.82)\end{array}$ & & $\begin{array}{c}1.85^{* * *} \\
(7.40)\end{array}$ & & $\begin{array}{c}2.45^{* * *} * \\
(9.89)\end{array}$ & & $\begin{array}{c}2.93 * * * \\
(11.43)\end{array}$ & \\
\hline$F$ & $\begin{array}{c}0.17 \\
(0.87)\end{array}$ & & $\begin{array}{c}0.20 \\
(1.26)\end{array}$ & & $\begin{array}{c}0.16 \\
(1.20)\end{array}$ & & $\begin{array}{l}0.17^{*} \\
(1.95)\end{array}$ & \\
\hline$S$ & $\begin{array}{c}0.02 * * * \\
(14.74)\end{array}$ & $\begin{array}{c}0.02 * * * \\
(15.02)\end{array}$ & $\begin{array}{c}0.02 * * * \\
(16.43)\end{array}$ & $\begin{array}{c}0.02 * * * \\
(17.15)\end{array}$ & $\begin{array}{c}0.03 * * * \\
(19.96)\end{array}$ & $\begin{array}{c}0.03 * * * \\
(21.00)\end{array}$ & $\begin{array}{c}0.03 * * * \\
(24.02)\end{array}$ & $\begin{array}{c}0.03 * * * \\
(26.31)\end{array}$ \\
\hline Leverage & $\begin{array}{c}0.07 \\
(0.01)\end{array}$ & $\begin{array}{c}0.45 \\
(0.10)\end{array}$ & $\begin{array}{c}2.35 \\
(0.85)\end{array}$ & $\begin{array}{c}2.94 \\
(1.06)\end{array}$ & $\begin{array}{c}1.64 \\
(0.61)\end{array}$ & $\begin{array}{c}2.53 \\
(0.91)\end{array}$ & $\begin{array}{c}1.79 \\
(0.70)\end{array}$ & $\begin{array}{c}3.16 \\
(1.17)\end{array}$ \\
\hline Stock volatility & $\begin{array}{c}0.78 \\
(0.19)\end{array}$ & $\begin{array}{c}2.01 \\
(0.47)\end{array}$ & $\begin{array}{c}-4.22 \\
(-1.28)\end{array}$ & $\begin{array}{c}-1.70 \\
(-0.48)\end{array}$ & $\begin{array}{l}-5.62^{*} \\
(-1.89)\end{array}$ & $\begin{array}{c}-4.28 \\
(-1.33)\end{array}$ & $\begin{array}{c}0.70 \\
(0.24)\end{array}$ & $\begin{array}{c}3.27 \\
(1.10)\end{array}$ \\
\hline Log(stock volume) & $\begin{array}{c}0.36^{* * *} \\
(3.36)\end{array}$ & $\begin{array}{c}0.40^{* * * *} \\
(3.55)\end{array}$ & $\begin{array}{l}0.22 * * \\
(2.30)\end{array}$ & $\begin{array}{c}0.31 * * * \\
(3.05)\end{array}$ & $\begin{array}{c}0.33 * * * \\
(3.35)\end{array}$ & $\begin{array}{c}0.51 * * * \\
(4.77)\end{array}$ & $\begin{array}{c}0.26 * * * \\
(2.70)\end{array}$ & $\begin{array}{c}0.41 * * * \\
(3.94)\end{array}$ \\
\hline Log(bond volume) & $\begin{array}{c}0.01 \\
(0.69)\end{array}$ & $\begin{array}{c}0.02 \\
(0.76)\end{array}$ & $\begin{array}{c}0.00 \\
(0.26)\end{array}$ & $\begin{array}{c}0.01 \\
(0.43)\end{array}$ & $\begin{array}{c}-0.00 \\
(-0.11)\end{array}$ & $\begin{array}{c}0.01 \\
(0.52)\end{array}$ & $\begin{array}{c}-0.01 \\
(-0.80)\end{array}$ & $\begin{array}{c}0.00 \\
(0.00)\end{array}$ \\
\hline $\log ($ bond Amihud $)$ & $\begin{array}{c}0.01 \\
(0.64)\end{array}$ & $\begin{array}{c}0.01 \\
(0.69)\end{array}$ & $\begin{array}{c}0.02 \\
(1.05)\end{array}$ & $\begin{array}{c}0.02 \\
(1.25)\end{array}$ & $\begin{array}{c}0.00 \\
(0.28)\end{array}$ & $\begin{array}{c}0.01 \\
(0.78)\end{array}$ & $\begin{array}{c}0.00 \\
(0.34)\end{array}$ & $\begin{array}{c}0.02 \\
(1.35)\end{array}$ \\
\hline Stock bid-ask spread & $\begin{array}{c}0.00 \\
(0.03)\end{array}$ & $\begin{array}{c}-0.00 \\
(-0.31)\end{array}$ & $\begin{array}{l}0.00^{*} \\
(1.73)\end{array}$ & $\begin{array}{c}0.00 \\
(1.16)\end{array}$ & $\begin{array}{l}0.00 * * \\
(2.01)\end{array}$ & $\begin{array}{c}0.00 \\
(1.62)\end{array}$ & $\begin{array}{c}0.00 \\
(0.50)\end{array}$ & $\begin{array}{c}0.00 \\
(0.11)\end{array}$ \\
\hline LOIS & $\begin{array}{c}2.01 * * * \\
(5.49)\end{array}$ & $\begin{array}{c}3.18 * * * \\
(9.46)\end{array}$ & $\begin{array}{c}1.67 * * * \\
(7.19)\end{array}$ & $\begin{array}{c}2.66^{* * * *} \\
(11.32)\end{array}$ & $\begin{array}{c}0.91 * * * \\
(4.55)\end{array}$ & $\begin{array}{c}1.68^{* * *} \\
(8.93)\end{array}$ & $\begin{array}{c}-0.14 \\
(-1.00)\end{array}$ & $\begin{array}{c}0.30 * * \\
(2.45)\end{array}$ \\
\hline$V I X^{\prime}$ & $\begin{array}{c}0.01 \\
(1.37)\end{array}$ & $\begin{array}{l}0.02^{*} \\
(1.89)\end{array}$ & $\begin{array}{c}-0.03 * * * \\
(-3.64)\end{array}$ & $\begin{array}{l}-0.02 * * \\
(-2.54)\end{array}$ & $\begin{array}{c}-0.06 * * * \\
(-9.48)\end{array}$ & $\begin{array}{c}-0.07 * * * \\
(-11.01)\end{array}$ & $\begin{array}{c}-0.03 * * * \\
(-5.04)\end{array}$ & $\begin{array}{c}-0.02 * * * \\
(-3.62)\end{array}$ \\
\hline Observations & 29,079 & 29,079 & 38,758 & 38,758 & 47,546 & 47,546 & 57,727 & 57,727 \\
\hline R-squared & 0.344 & 0.336 & 0.435 & 0.424 & 0.472 & 0.457 & 0.499 & 0.479 \\
\hline Number of firms & 344 & 344 & 350 & 350 & 358 & 358 & 369 & 369 \\
\hline
\end{tabular}


Panel B: Overall effect of the CDS Small Bang on the bid-ask spread

\begin{tabular}{|c|c|c|c|c|c|c|c|c|}
\hline & (1) & (2) & (3) & (4) & $(5)$ & (6) & (7) & (8) \\
\hline & $3 \mathrm{M}$ & $3 \mathrm{M}$ & $4 \mathrm{M}$ & $4 \mathrm{M}$ & $5 \mathrm{M}$ & $5 \mathrm{M}$ & $6 \mathrm{M}$ & $6 \mathrm{M}$ \\
\hline \multirow[t]{2}{*}{$S B$} & $-2.26 * * *$ & $-2.36 * * *$ & $-2.32 * * *$ & $-2.53 * * *$ & $-2.17 * * *$ & $-2.41 * * *$ & $-1.98 * * *$ & $-2.22 * * *$ \\
\hline & $(-12.25)$ & $(-12.22)$ & $(-12.50)$ & $(-12.39)$ & $(-11.64)$ & $(-11.76)$ & $(-10.67)$ & $(-11.03)$ \\
\hline \multirow[t]{2}{*}{$F X S B$} & $2.31 * * *$ & & $2.31 * * *$ & & $2.22 * * *$ & & $2.24 * * *$ & \\
\hline & $(4.23)$ & & $(4.18)$ & & (4.13) & & $(4.16)$ & \\
\hline \multirow[t]{2}{*}{$F$} & 0.26 & & $1.48 * * *$ & & $1.56^{* * *}$ & & $1.76^{* * *}$ & \\
\hline & $(0.37)$ & & $(2.66)$ & & $(3.50)$ & & $(4.41)$ & \\
\hline \multirow[t]{2}{*}{$S$} & $0.03 * * *$ & $0.03 * * *$ & $0.03 * * *$ & $0.03 * * *$ & $0.03 * * *$ & $0.04 * * *$ & $0.04 * * *$ & $0.04 * * *$ \\
\hline & $(8.88)$ & $(9.95)$ & $(10.53)$ & (11.89) & $(14.34)$ & $(15.74)$ & $(17.01)$ & (19.26) \\
\hline \multirow[t]{2}{*}{ Stock bid-ask spread } & 0.61 & 0.48 & -0.19 & -0.35 & 0.73 & 0.90 & $3.00 *$ & $3.56^{*}$ \\
\hline & $(0.68)$ & $(0.53)$ & $(-0.11)$ & $(-0.19)$ & $(0.38)$ & $(0.45)$ & (1.69) & $(1.82)$ \\
\hline \multirow[t]{2}{*}{$\log ($ stock volume $)$} & 0.06 & 0.06 & 0.09 & 0.08 & 0.12 & 0.11 & 0.13 & 0.13 \\
\hline & $(0.66)$ & $(0.61)$ & $(1.03)$ & $(0.88)$ & $(1.43)$ & $(1.33)$ & $(1.63)$ & $(1.58)$ \\
\hline \multirow[t]{2}{*}{ VSTOXX } & $-0.04 * *$ & -0.03 & $-0.06 * * *$ & $-0.08 * * *$ & $-0.08 * * *$ & $-0.10 * * *$ & $-0.12 * * *$ & $-0.14 * * *$ \\
\hline & $(-2.08)$ & $(-1.64)$ & $(-3.83)$ & $(-4.29)$ & $(-6.02)$ & $(-6.46)$ & $(-10.70)$ & $(-10.02)$ \\
\hline \multirow[t]{2}{*}{ LOIS Euro } & $4.44 * * *$ & $3.67 * * *$ & $4.58 * * *$ & $4.99 * * *$ & $5.99 * * *$ & $6.62 * * *$ & $8.01 * * *$ & $8.59^{* * *}$ \\
\hline & $(6.11)$ & $(4.96)$ & $(7.48)$ & $(8.89)$ & (11.29) & (12.84) & $(15.53)$ & (17.98) \\
\hline Observations & 23,151 & 23,151 & 30,784 & 30,784 & 39,045 & 39,045 & 45,282 & 45,282 \\
\hline R-squared & 0.404 & 0.392 & 0.500 & 0.483 & 0.579 & 0.566 & 0.630 & 0.618 \\
\hline Number of firms & 288 & 288 & 295 & 295 & 301 & 301 & 305 & 305 \\
\hline
\end{tabular}

